\title{
Impact of H1N1 on Socially Disadvantaged Populations: Systematic Review
}

\author{
Andrea C. Tricco ${ }^{1}$, Erin Lillie ${ }^{1}$, Charlene Soobiah ${ }^{1,2}$, Laure Perrier ${ }^{1,3}$, Sharon E. Straus ${ }^{1,4 *}$ \\ 1 Li Ka Shing Knowledge Institute of St Michael's Hospital, Toronto, Ontario, Canada, 2 Child Health Evaluative Sciences, The Hospital for Sick Children, Toronto, Ontario, \\ Canada, 3 Continuing Education and Professional Development, University of Toronto, Toronto, Ontario, Canada, 4 Division of Geriatrics, Faculty of Medicine, University of \\ Toronto, Toronto, Ontario, Canada
}

\begin{abstract}
Background: The burden of $\mathrm{H} 1 \mathrm{~N} 1$ among socially disadvantaged populations is unclear. We aimed to synthesize hospitalization, severe illness, and mortality data associated with pandemic A/H1N1/2009 among socially disadvantaged populations.

Methods/Principal Findings: Studies were identified through searching MEDLINE, EMBASE, scanning reference lists, and contacting experts. Studies reporting hospitalization, severe illness, and mortality attributable to laboratory-confirmed 2009 H1N1 pandemic among socially disadvantaged populations (e.g., ethnic minorities, low-income or lower-middle-income economy countries [LIC/LMIC]) were included. Two independent reviewers conducted screening, data abstraction, and quality appraisal (Newcastle Ottawa Scale). Random effects meta-analysis was conducted using SAS and Review Manager.

Conclusions/Significance: Sixty-two studies including 44,777 patients were included after screening 787 citations and 164 full-text articles. The prevalence of hospitalization for H1N1 ranged from 17-87\% in high-income economy countries (HIC) and $11-45 \%$ in LIC/LMIC. Of those hospitalized, the prevalence of intensive care unit (ICU) admission and mortality was 6$76 \%$ and $1-25 \%$ in HIC; and $30 \%$ and $8-15 \%$, in LIC/LMIC, respectively. There were significantly more hospitalizations among ethnic minorities versus non-ethnic minorities in two studies conducted in North America (1,313 patients, OR 2.26 [95\% Cl: 1.53-3.32]). There were no differences in ICU admissions ( $n=8$ studies, 15,352 patients, OR 0.84 [0.69-1.02]) or deaths ( $n=6$ studies, 14,757 patients, OR 0.85 [95\% Cl: 0.73-1.01]) among hospitalized patients in HIC. Sub-group analysis indicated that the meta-analysis results were not likely affected by confounding. Overall, the prevalence of hospitalization, severe illness, and mortality due to H1N1 was high for ethnic minorities in HIC and individuals from LIC/LMIC. However, our results suggest that there were little differences in the proportion of hospitalization, severe illness, and mortality between ethnic minorities and non-ethnic minorities living in HIC.
\end{abstract}

Citation: Tricco AC, Lillie E, Soobiah C, Perrier L, Straus SE (2012) Impact of H1N1 on Socially Disadvantaged Populations: Systematic Review. PLoS ONE 7(6): e39437. doi:10.1371/journal.pone.0039437

Editor: Steven J. Drews, University of Calgary \& ProvLab Alberta, Canada

Received January 25, 2012; Accepted May 22, 2012; Published June 25, 2012

Copyright: (c) 2012 Tricco et al. This is an open-access article distributed under the terms of the Creative Commons Attribution License, which permits unrestricted use, distribution, and reproduction in any medium, provided the original author and source are credited.

Funding: This systematic review was partially funded by the World Health Organization (WHO), Global Influenza Programme (http://www.who.int/influenza/ about/en/). The funders had no role in study design, data collection and analysis, decision to publish, or the preparation of the manuscript. Sharon E. Straus is funded by a Tier 1 Canada Research Chair through the Canadian Institutes for Health Research.

Competing Interests: The authors have the following interests: ACT has been a paid consultant to examine cross-protection of non-influenza vaccine types for GlaxoSmithKline. This does not alter the authors' adherence to all the PLoS ONE policies on sharing data and materials. The other authors have nothing to declare.

*E-mail: sharon.straus@utoronto.ca

\section{Introduction}

In 2009, a novel H1N1 influenza virus strain circulated, which gave rise to the $2009 \mathrm{H} 1 \mathrm{Nl}$ pandemic (influenza A/Mexico/2009 $(\mathrm{H} 1 \mathrm{Nl}))$. The $\mathrm{H} 1 \mathrm{Nl}$ pandemic was associated with a high burden of illness in terms of hospitalizations, severe illness, absenteeism, and cost. For example, in the United States (US), over 43,677 laboratory-confirmed cases of pandemic H1Nl 2009 were reported [1]. Using a mathematical model, it was estimated that between 1.8 million to 5.7 million cases occurred, including 9,000 to 21,000 hospitalizations in the US [1]. In Spain, the average work absenteeism due to the $2009 \mathrm{H} 1 \mathrm{~N} 1$ pandemic ranged from 9 to 30.5 days [2]. The economic burden for those with confirmed influenza was estimated as $€ 144,773,577$ in Spain $(95 \%$ confidence interval, CI: 13,753,043-383,467,535). In Italy, the estimated economic burden due to laboratory-confirmed $\mathrm{H} 1 \mathrm{~N} 1$
2009 pandemic ranged from $€ 1.3$ to $€ 2.3$ billion [3]. In Australia, the economic burden of treating $\mathrm{H} 1 \mathrm{Nl}$-admitted patients to the intensive care unit (ICU) was over AU \$65,000,000 [4]. These estimates indicate that a significant burden of illness was observed due to the $2009 \mathrm{H} 1 \mathrm{Nl}$ pandemic

Previous reviews of the $2009 \mathrm{H} 1 \mathrm{~N} 1$ pandemic reported that the majority of cases occurred among young to middle-aged adults often in those without comorbidity, followed by children and adolescents [5,6]. Individuals with a greater burden of illness included the elderly, obese individuals, pregnant women, or those with comorbidity $[5,6]$. In addition, it has been hypothesized that greater burden of illness was associated with poverty and individuals without access or disproportionate access to healthcare [7]. To examine this further, we aimed to synthesize hospitalization, severe illness, and mortality data associated with pandemic A/H1N1/2009 among socially disadvantaged populations, in- 
cluding low socioeconomic status, ethnic minorities, groups without access or disproportionate access to healthcare, and lowincome economy countries or lower-middle-income economy countries [LIC/LMIG].

\section{Methods}

A systematic review protocol was used to guide the methods of our review, based on the Preferred Reporting Items for Systematic Reviews and Meta-analysis (PRISMA) Statement [8]. Our research question was: "what is the evidence that the burden of H1N1 was associated with social disadvantage?" At the time of study conduct, a similar systematic review protocol focusing on H1N1 burden among the socially disadvantaged did not exist.

\section{Search}

An experienced librarian (Perrier) developed the search strategy using medical subject headings $(\mathrm{MeSH})$ and text words. The MEDLINE (OVID interface, 2009 to July 25, 2011) and EMBASE (OVID interface, 2009 to July 25, 2011) electronic databases were searched to identify potentially relevant material. The full search strategy for MEDLINE is presented in Appendix $\mathrm{S} 1$, which was modified for EMBASE (available upon request). Targeted searching for low-income and lower-middle-income economies was also conducted in PubMed using the terms "H1N1" and "country of interest". The Eurosurveillance Journal and the Centers for Disease Control and Prevention (CDC) Morbidity and Mortality Weekly Report were hand-searched from January 2009 until August 1, 2011. The reference lists of included studies or relevant reviews $[5,6,9]$ were scanned and a list of included studies was circulated to members of the World Health Organization (WHO) Influenza Programme to ensure all potentially relevant studies were identified.

\section{Study Selection and Characteristics}

Studies reporting the burden (prevalence of hospitalization, severe illness, and mortality) of influenza A/Mexico/2009 (H1Nl) among socially disadvantaged populations (e.g., ethnic minorities, low socioeconomic status, groups without access or disproportionate access to healthcare, LIC/LMIG) were included. It was determined a priori in discussion with the World Health Organization (organization that commissioned this systematic review) that burden would include hospitalization, severe illness, and mortality. $\mathrm{H} 1 \mathrm{Nl}$ had to be laboratory-confirmed through polymerase chain reaction, viral culture, or antibody assay [10], as each laboratory test has various advantages and limitations [11]. For example, antibody assay can detect infections missed by other laboratory methods but the diagnosis of influenza is retrospective and it takes weeks to retrieve the results [11]. According to the Center for Disease Control and Prevention (CDC), the preferred method of pandemic H1Nl 2009 influenza ascertainment was polymerase chain reaction and viral culture [12]. Rapid influenza diagnostic tests were not recommended by the CDC (and hence, were excluded from this systematic review), as their sensitivity is low [10].

Ethnic minorities were classified as non-predominant races (e.g., non-Caucasians in predominant Caucasian continents, such as Europe and North America), as well as indigenous populations (i.e., first settlers in a particular territory [9]). LIC (gross national income $\leq \$ 1,005$ ) and LMIC (gross national income $\$ 1,006$ $\$ 3,975$ ) were categorized according to the World Bank's classification of countries [13]. We planned to classify low socioeconomic status as high-school education or less or below the particular country's poverty line, but we did not identify articles relevant to this type of social disadvantage [14]. Inclusion was not limited by study design, publication status or language. Authors of conference proceedings were contacted to obtain the conference presentation or unpublished work. Two reviewers independently screened the titles and abstracts from the literature search and potentially relevant full-text articles for inclusion using the standardized eligibility criteria. Conflicts were resolved by discussion amongst the team.

\section{Data Abstraction}

A draft data abstraction form was developed, pilot-tested, and modified as necessary. Two reviewers abstracted all of the data independently. Conflicts were resolved by discussion amongst the review team. The following data were abstracted: study characteristics (e.g., study design, country of conduct, time period), patient characteristics (e.g., mean age, percent gender, type of social disadvantage examined) and outcomes (number of hospitalizations, severe illness, deaths). Authors were contacted for further information when the data were not clearly reported. In some instances, multiple studies reported $\mathrm{H} 1 \mathrm{~N} 1$ data from the same source (i.e., companion reports). When this occurred, the report with the most outcomes of interest or largest sample size was included and the other(s) was used for supplementary material only.

\section{Validity Assessment}

All relevant studies were assessed for risk of bias using the Newcastle Ottawa Scale (NOS) [15]. The NOS evaluates nonrandomized studies such as case-control and cohort studies and consists of 3 domains: selection, comparability, and exposure. A full explanation of the NOS can be found in Appendix S2.

\section{Quantitative Data Synthesis}

Random effects meta-analysis [16] was conducted to determine the prevalence of hospitalization, ICU admission, and mortality that occurred in high-income economy countries (HIC) and LIC/ LMIC, separately, as well as for the proportion of ethnic minorities and non-ethnic minorities experiencing these outcomes in HIC. Confounding was examined through meta-analyses of the proportion of patients with comorbidity, pregnancy, and obesity for ethnic minorities versus non-ethnic minorities in HIC. Statistical heterogeneity was examined using the $\mathrm{I}^{2}$ and $\chi^{2}$ statistics [17]. Analyses were conducted in Review Manager Version 5 [18] and SAS (SAS 9.1 software, SAS Institute Inc., Cary, NG, USA).

\section{Results}

\section{Flow of Included Studies}

The literature search identified 787 titles and abstracts; 164 were potentially relevant (Figure 1, Flowchart S1, Checklist S1). From these, 62 articles fulfilled the eligibility criteria [19-80]. Of these, fourteen articles were companion reports and only supplementary data were obtained from them [23,27,31,34, $36,50,54,55,57,71,75-78]$. All of the studies were written in English and unpublished data were obtained for two studies identified by contacting authors of excluded studies [33,35].

\section{Study Characteristics}

The majority of the included studies were conducted in HIC, including the United States [20,21,24,28-30,32,35,37-40,42,45, 46,48,62], Australia or New Zealand [22,43,44,49,51,53,56, 59,63], Canada [19,25,26,33,47], and the United Kingdom $[41,52,58]$ (Table 1). Twelve studies were conducted in LIC/ 


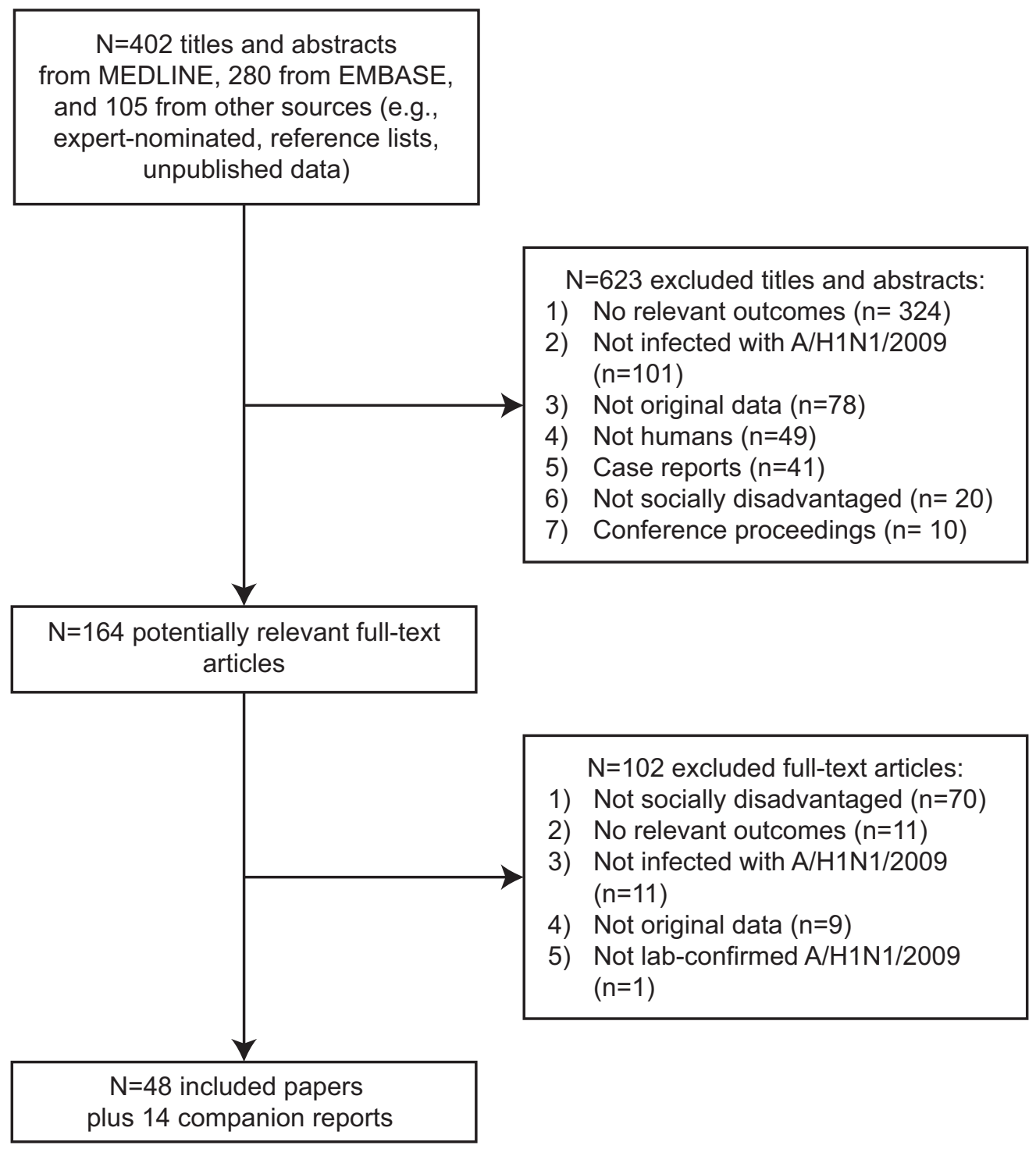

Figure 1. Study flow. This is the flow of citations and articles that were screened for the systematic review. doi:10.1371/journal.pone.0039437.g001

LMIC, including Guatemala [64], Morocco [65,66], Pakistan [80], and India [67-78]. All of the included studies were cohort studies.

Across the studies, the time period of examination ranged from March 1, 2009 to October 24, 2010. Most studies used PGR to confirm H1N1 infection (44/48); one study reported the use of nasopharyngeal swabs (type of lab-confirmation unspecified) [63], and two studies reported that $\mathrm{H} 1 \mathrm{Nl}$ was lab-confirmed, without reporting the type of test used [44,58]. The majority of studies examined ethnic minority status as the type of social disadvantage (36/48), except for 12 studies that examined H1N1 in LIC/LMIC [64-70,72-74,79,80].

\section{Patient Characteristics}

Some studies examined differences in the number of hospitalizations, severe illness, and deaths between ethnic minorities and non-ethnic minorities, including Caucasian, European descent, and non-Indigenous populations, which were used as the reference group (Table 2). The number of $\mathrm{H} 1 \mathrm{~N} 1$-infected individuals ranged from 136 to 5,106 in the included studies (Tables 2 and 3). Few studies reported the percentage of female participants; in those that did report this, it ranged from $24 \%$ to $100 \%$ (Tables 2 and 3 ).

Two studies included only pregnant women infected with $\mathrm{H} 1 \mathrm{~N} 1$ $[19,28]$ and 14 others reported on pregnancies among socially disadvantaged populations $[21,30,43,46,49,64-66,68,70,72-$ $74,80]$. No significant differences were observed between the proportion of pregnancies in ethnic minorities and non-ethnic minorities in HIC ( $\mathrm{n}=765$ patients, OR 0.31 , 95\% CI: $0.03-3.64)$ $[30,43,46,49]$. Six studies included only H1N1-infected children and adolescents [20,42,47,58,69,79] and two studies reported deaths in pediatric patients (although the number of hospitalizations was for the entire population including all ages for one study) [20,32]. Twenty-one studies reported comorbidities among the socially disadvantaged; including asthma, chronic lung conditions, heart conditions, and diabetes [20,21,24,29,30,40,43,49,56,6470,72-74,79,80]; all studies conducted in LIC/LMIC reported this information. For HIC studies, there was no significant difference observed between ethnic minorities and non-ethnic minorities in terms of prevalent comorbidities $(n=1,203$ patients, OR 1.14, 95\% CI: 0.63-2.06; Appendix S3) [20,24,29,30,43,49]. 
Table 1. Study characteristics.

\begin{tabular}{|c|c|c|c|c|c|}
\hline $\begin{array}{l}\text { First author, } \\
\text { Year }\end{array}$ & Time period & $\begin{array}{l}\text { Region of } \\
\text { conduct }\end{array}$ & Data source(s) & $\begin{array}{l}\text { Number of lab-confirmed } \\
\text { H1N1 [confirmation type] }\end{array}$ & Outcome(s) examined \\
\hline \multicolumn{6}{|c|}{ ETHNIC MINORITIES } \\
\hline $\begin{array}{l}\text { Oluyomi-Obi } \\
2010 \text { [19] }\end{array}$ & $\begin{array}{l}\text { March 1- } \\
\text { August } \\
312009\end{array}$ & $\begin{array}{l}\text { Manitoba, } \\
\text { Canada }\end{array}$ & $\begin{array}{l}\text { St. Boniface Hospital } \\
\text { \& Health Sciences Centre ICU }\end{array}$ & $889[\mathrm{PCR}]$ & ICU admission \\
\hline $\begin{array}{l}\text { CDC Sept } \\
2009[20]\end{array}$ & $\begin{array}{l}\text { April-August } \\
82009\end{array}$ & US & $\begin{array}{l}\mathrm{CDC} \text { influenza-associated } \\
\text { pediatric mortality reporting system }\end{array}$ & 36 pediatric deaths [RT-PCR] & Mortality \\
\hline $\begin{array}{l}\text { Martin } \\
2010[21]\end{array}$ & $\begin{array}{l}\text { April 1- } \\
\text { October } \\
312009\end{array}$ & $\begin{array}{l}\text { North } \\
\text { Carolina, } \\
\text { US }\end{array}$ & $\begin{array}{l}\text { Duke University } \\
\text { Medical Center }\end{array}$ & $\begin{array}{l}123 \text { hospitalizations } \\
\text { [RT-PCR, viral culture] }\end{array}$ & Hospitalization \\
\hline $\begin{array}{l}\text { Paine } \\
2010[22]^{*}(1)\end{array}$ & $\begin{array}{l}\text { April 1- } \\
\text { November } \\
12009\end{array}$ & $\begin{array}{l}\text { New } \\
\text { Zealand }\end{array}$ & EpiSurv & $\begin{array}{l}3067[P C R \text {, viral culture, } \\
\text { antibody assay] }\end{array}$ & Mortality \\
\hline $\begin{array}{l}\text { Baker } \\
2009 \text { [23] (1) }\end{array}$ & $\begin{array}{l}\text { April 25- } \\
\text { August } \\
232009\end{array}$ & $\begin{array}{l}\text { New } \\
\text { Zealand }\end{array}$ & $\begin{array}{l}\text { Surveillance data from notifiable } \\
\text { disease, general practices, } \\
\text { laboratories, Healthline, Ministry } \\
\text { of Health ICU, population survey } \\
\text { (Flutracker) }\end{array}$ & $\begin{array}{l}3109[\mathrm{PCR}, \text { viral culture, } \\
\text { antibody assay] }\end{array}$ & Hospitalization \\
\hline $\begin{array}{l}\text { Wenger } \\
2011 \text { [24] }\end{array}$ & $\begin{array}{l}\text { April 1- } \\
\text { December } \\
312009\end{array}$ & Alaska, US & $\begin{array}{l}\text { Alaska ILI Surveillance Network, } \\
\text { Medicaid, Indian Health Service } \\
\text { Influenza Awareness System }\end{array}$ & $\begin{array}{l}103 \text { hospitalizations } \\
{[\mathrm{PCR} \text {, viral culture }]}\end{array}$ & Hospitalization, mortality \\
\hline $\begin{array}{l}\text { Zarychanski } \\
2010 \text { [25] }\end{array}$ & $\begin{array}{l}\text { April 2- } \\
\text { September } \\
52009\end{array}$ & $\begin{array}{l}\text { Manitoba, } \\
\text { Canada }\end{array}$ & $\begin{array}{l}\text { Manitoba Health and University } \\
\text { of Manitoba Critical Care }\end{array}$ & $\begin{array}{l}894 \text { (location known } \\
\text { for 795) [RT-PCR] }\end{array}$ & Hospitalization, ICU admission \\
\hline $\begin{array}{l}\text { Helferty } \\
2010[26]^{*}(2)\end{array}$ & $\begin{array}{l}\text { April } 12 \\
\text { 2009- } \\
\text { April } 32010\end{array}$ & Canada & PHAC & $\begin{array}{l}8678 \text { hospitalizations } \\
\text { [RT-PCR, viral culture, } \\
\text { antibody assay] }\end{array}$ & $\begin{array}{l}\text { Hospitalization, ICU admission, } \\
\text { mortality }\end{array}$ \\
\hline $\begin{array}{l}\text { Campbell } \\
2010[27](2)\end{array}$ & $\begin{array}{l}\text { April 26- } \\
\text { September } \\
262009\end{array}$ & Canada & PHAC & $\begin{array}{l}1479 \text { hospitalizations } \\
\text { [RT-PCR, viral culture, antibody } \\
\text { assay] }\end{array}$ & $\begin{array}{l}\text { Hospitalization, ICU admission, } \\
\text { mortality }\end{array}$ \\
\hline $\begin{array}{l}\text { Siston } \\
2010[28]\end{array}$ & $\begin{array}{l}\text { April } 14- \\
\text { August } \\
212009\end{array}$ & US & CDC (Pregnancy Flu Line) & $\begin{array}{l}788 \text { pregnant women [rRT-PCR, } \\
\text { antibody assay, rapid test, viral } \\
\text { culture] }\end{array}$ & $\begin{array}{l}\text { Hospitalization, ICU admission, } \\
\text { mortality }\end{array}$ \\
\hline $\begin{array}{l}\text { CDC Dec } \\
2009[29]\end{array}$ & $\begin{array}{l}\text { April 15- } \\
\text { November } 13 \\
2009\end{array}$ & US & $\begin{array}{l}\text { Multidisciplinary workgroup from } \\
12 \text { state health departments }\end{array}$ & $\begin{array}{l}\text { NR [rapid test, antibody assay, } \\
\text { rRT-PCR, viral culture] }\end{array}$ & Mortality \\
\hline $\begin{array}{l}\text { Chitnis } \\
2010[30]^{*}(3)\end{array}$ & $\begin{array}{l}\text { April 23- } \\
\text { August } \\
152009\end{array}$ & $\begin{array}{l}\text { Wisconsin, } \\
\text { US }\end{array}$ & Wisconsin Division of Public Health & 252 hospitalizations [rRT-PCR] & $\begin{array}{l}\text { Hospitalization, ICU admission, } \\
\text { mortality }\end{array}$ \\
\hline $\begin{array}{l}\text { Truelove } \\
2011[31] \text { (3) }\end{array}$ & $\begin{array}{l}\text { April } 15 \\
2009-J a n u a r y \\
22010\end{array}$ & $\begin{array}{l}\text { Wisconsin, } \\
\text { US }\end{array}$ & Wisconsin Division of Public Health & 1266 [rRT-PCR] & Hospitalization, mortality \\
\hline $\begin{array}{l}\text { Dee } \\
2011[32]\end{array}$ & $\begin{array}{l}\text { April } 152009- \\
\text { January } 262010 \\
\text { hospitalization } \\
\text { (pediatric deaths: } \\
\text { April } 152009- \\
\text { March } 232010 \text { ) }\end{array}$ & US & $\begin{array}{l}\text { Emerging Infections Program (CDC, } \\
10 \text { state and local health departments, } \\
\text { academic institutions, medical } \\
\text { providers), CDC Influenza- } \\
\text { Associated Pediatric Mortality } \\
\text { Surveillance System }\end{array}$ & $\begin{array}{l}5793 \text { hospitalizations [rapid test, } \\
\text { RT-PCR, viral culture, docu- } \\
\text { mented in medical chart] }\end{array}$ & Hospitalization, mortality \\
\hline $\begin{array}{l}\text { Jung } 2011 \\
{[33]^{*}(4)} \\
\text { unpublished } \\
\text { data }\end{array}$ & $\begin{array}{l}\text { April } 162009- \\
\text { April } 122010\end{array}$ & Canada & $\begin{array}{l}\text { Canadian Critical Care } \\
\text { Trials Group }\end{array}$ & $\begin{array}{l}565 \text { critically ill [rRT-PCR, viral } \\
\text { culture] }\end{array}$ & ICU admission \\
\hline $\begin{array}{l}\text { Jouvet } \\
2010[34](4)\end{array}$ & $\begin{array}{l}\text { April 16- } \\
\text { August } 152009\end{array}$ & Canada & $\begin{array}{l}\text { Canadian Critical Care } \\
\text { Trials Group }\end{array}$ & $\begin{array}{l}49 \text { pediatric ICU admissions } \\
{[P C R \text {, viral culture }]}\end{array}$ & Pediatric ICU admission \\
\hline $\begin{array}{l}\text { Louie } 2011 \\
{[35]^{*}(5)} \\
\text { unpublished } \\
\text { data }\end{array}$ & $\begin{array}{l}\text { April } 12009- \\
\text { August } 132010\end{array}$ & $\begin{array}{l}\text { California, } \\
\text { US }\end{array}$ & $\begin{array}{l}\text { California Department of } \\
\text { Public Health }\end{array}$ & $\begin{array}{l}2476 \text { hospitalizations } \\
\text { [rRT-PCR] }\end{array}$ & $\begin{array}{l}\text { Hospitalization, ICU admission, } \\
\text { mortality }\end{array}$ \\
\hline $\begin{array}{l}\text { CDC May } \\
2009[36](5)\end{array}$ & $\begin{array}{l}\text { April 20-May } \\
172009\end{array}$ & $\begin{array}{l}\text { California, } \\
\text { US }\end{array}$ & $\begin{array}{l}\text { California Department of } \\
\text { Public Health }\end{array}$ & $\begin{array}{l}333 \text { hospitalizations } \\
\text { [rRT-PCR] }\end{array}$ & Hospitalization \\
\hline Lee 2010 [37] & $\begin{array}{l}\text { April 24-July } \\
12009\end{array}$ & $\begin{array}{l}\text { New York City, } \\
\text { US }\end{array}$ & $\begin{array}{l}\text { New York City Department of } \\
\text { Health and Mental Hygiene, New York } \\
\text { City Office of Vital Statistics (death } \\
\text { certificates) }\end{array}$ & 47 deaths [rRT-PCR] & Mortality \\
\hline
\end{tabular}


Table 1. Cont.

\begin{tabular}{|c|c|c|c|c|c|}
\hline $\begin{array}{l}\text { First author, } \\
\text { Year }\end{array}$ & Time period & $\begin{array}{l}\text { Region of } \\
\text { conduct }\end{array}$ & Data source(s) & $\begin{array}{l}\text { Number of lab-confirmed } \\
\text { H1N1 [confirmation type] }\end{array}$ & Outcome(s) examined \\
\hline $\begin{array}{l}\text { CDC Aug } \\
2009[38]\end{array}$ & $\begin{array}{l}\text { April 24-July } \\
252009\end{array}$ & Illinois, US & Chicago Department of Public Health & 1557 [rRT-PCR] & Hospitalization \\
\hline $\begin{array}{l}\text { CDC Jan } \\
2010[39]\end{array}$ & $\begin{array}{l}\text { April 25-May } \\
242009\end{array}$ & $\begin{array}{l}\text { New York } \\
\text { City, US }\end{array}$ & $\begin{array}{l}\text { New York City Department } \\
\text { of Health and Mental Hygiene } \\
\text { (all hospitals) }\end{array}$ & 99 hospitalizations [PCR] & Hospitalization \\
\hline $\begin{array}{l}\text { Kwan-Gett } \\
2009[40]\end{array}$ & $\begin{array}{l}\text { April 25-August } \\
72009\end{array}$ & $\begin{array}{l}\text { Washington, } \\
\text { US }\end{array}$ & $\begin{array}{l}\text { Public Health-Seattle } \\
\text { \& King County }\end{array}$ & 565 [viral culture, PCR] & Mortality \\
\hline $\begin{array}{l}\text { Nguyen- } \\
\text { Van-Tam } \\
2010[41]\end{array}$ & $\begin{array}{l}\text { April 27-Sept } 30 \\
2009\end{array}$ & UK & $\begin{array}{l}\text { The Influenza Clinical } \\
\text { Information Network } \\
\text { (FluCAN) }\end{array}$ & 631 hospitalizations [rRT-PCR] & Hospitalization \\
\hline $\begin{array}{l}\text { Kumar } \\
2010[42]\end{array}$ & $\begin{array}{l}\text { April 28-August } \\
312009\end{array}$ & $\begin{array}{l}\text { Wisconsin, } \\
\text { US }\end{array}$ & $\begin{array}{l}\text { Children's Hospital of } \\
\text { Wisconsin }\end{array}$ & 81 hospitalizations [rRT-PCR] & Hospitalization, mortality \\
\hline $\begin{array}{l}\text { Harris } \\
2010[43]\end{array}$ & $\begin{array}{l}\text { April-August } \\
2009\end{array}$ & $\begin{array}{l}\text { Queensland, } \\
\text { Australia }\end{array}$ & Townsville Hospital & $360[\mathrm{rPCR}]$ & $\begin{array}{l}\text { Hospitalization, ICU admission, } \\
\text { mortality }\end{array}$ \\
\hline $\begin{array}{l}\text { Kelly } \\
2009 \text { [44] }\end{array}$ & $\begin{array}{l}\text { May-October } \\
2009\end{array}$ & Australia & $\begin{array}{l}\text { Australian Department of } \\
\text { Health and Ageing }\end{array}$ & NR [lab-confirmed] & $\begin{array}{l}\text { Hospitalization, ICU admission, } \\
\text { mortality }\end{array}$ \\
\hline $\begin{array}{l}\text { Jain } \\
2009[45]\end{array}$ & $\begin{array}{l}\text { May 1-June } \\
92009\end{array}$ & US & $\begin{array}{l}\text { State health departments } \\
\text { reports to the CDC }\end{array}$ & 272 hospitalizations [rRT-PCR] & Hospitalization \\
\hline $\begin{array}{l}\text { Creanga } \\
2010[46]\end{array}$ & $\begin{array}{l}\text { May 1-June } \\
302009\end{array}$ & New York, US & $\begin{array}{l}\text { New York City Department } \\
\text { of Health and Mental Hygiene }\end{array}$ & 136 hospitalizations [rRT-PCR] & Hospitalization \\
\hline $\begin{array}{l}\text { Bettinger } \\
2010[47]\end{array}$ & $\begin{array}{l}\text { May 1-August } \\
312009\end{array}$ & Canada & $\begin{array}{l}\text { The Canadian Immunization } \\
\text { Monitoring Program, Active } \\
\text { (IMPACT) surveillance data }\end{array}$ & $\begin{array}{l}324 \text { hospitalizations [PCR, } \\
\text { antibody assay, viral culture] }\end{array}$ & Hospitalization \\
\hline $\begin{array}{l}\text { Miller } \\
2010[48]\end{array}$ & $\begin{array}{l}\text { May 19-June } \\
302009\end{array}$ & Utah, US & $\begin{array}{l}\text { Four ICUs at three academic } \\
\text { hospitals in Salt Lake County }\end{array}$ & 47 ICU admissions [PCR] & ICU admission \\
\hline $\begin{array}{l}\text { Flint } 2010 \\
{[49]^{*}(6)}\end{array}$ & $\begin{array}{l}\text { June 1-August } \\
312009\end{array}$ & $\begin{array}{l}\text { Northern } \\
\text { Territory, } \\
\text { Australia }\end{array}$ & $\begin{array}{l}\text { Northern Territory CDC, } \\
\text { Royal Darwin Hospital }\end{array}$ & 161 acute care [PCR] & Hospitalization, ICU admission \\
\hline $\begin{array}{l}\text { Flint } 2009 \\
{[50](6)}\end{array}$ & $\begin{array}{l}\text { May 29- June } \\
182009\end{array}$ & $\begin{array}{l}\text { Northern } \\
\text { Territory, } \\
\text { Australia }\end{array}$ & $\begin{array}{l}\text { Northern Territory CDC, } \\
\text { Royal Darwin Hospital }\end{array}$ & $81[\mathrm{PCR}]$ & Hospitalization \\
\hline $\begin{array}{l}\text { Cretikos } \\
2009[51]\end{array}$ & $\begin{array}{l}\text { May 15- } \\
\text { September } \\
42009\end{array}$ & $\begin{array}{l}\text { New South } \\
\text { Wales, Australia }\end{array}$ & $\begin{array}{l}\text { NetEpi, laboratory notifications, } \\
\text { hospital emergency department and } \\
\text { ambulance dispatch surveillance } \\
\text { system, death certificate surveillance }\end{array}$ & $5106[\mathrm{PCR}]$ & $\begin{array}{l}\text { Hospitalization, ICU admission, } \\
\text { mortality }\end{array}$ \\
\hline $\begin{array}{l}\text { Scriven } \\
2009[52]\end{array}$ & $\begin{array}{l}\text { June 1-July } \\
212009\end{array}$ & $\begin{array}{l}\text { Birmingham, } \\
\text { UK }\end{array}$ & Heartlands Hospital & $3000[\mathrm{PCR}]$ & Hospitalization, severe illness \\
\hline $\begin{array}{l}\text { Webb } 2009 \\
{[53]^{*}(7)}\end{array}$ & $\begin{array}{l}\text { June 1-August } \\
312009\end{array}$ & $\begin{array}{l}\text { New Zealand, } \\
\text { Australia }\end{array}$ & $\begin{array}{l}\text { Australian and New Zealand Intensive } \\
\text { Care Research Centre }\end{array}$ & $\begin{array}{l}722 \text { ICU admissions [PCR, } \\
\text { serology] }\end{array}$ & ICU admission \\
\hline $\begin{array}{l}\text { Knight } \\
2010[54](7)\end{array}$ & $\begin{array}{l}\text { June 1-August } \\
312009\end{array}$ & $\begin{array}{l}\text { Australia, } \\
\text { New Zealand }\end{array}$ & $\begin{array}{l}\text { Australian and New Zealand } \\
\text { Intensive Care Research Centre, } \\
\text { Australasian Maternity Outcomes } \\
\text { Surveillance System }\end{array}$ & $\begin{array}{l}59 \text { ICU pregnancy admissions } \\
\text { [confirmed H1N1] }\end{array}$ & ICU admission \\
\hline $\begin{array}{l}\text { ANZIC } \\
\text { Investigators } \\
2010[55](7)\end{array}$ & $\begin{array}{l}\text { June 1-August } \\
312009\end{array}$ & $\begin{array}{l}\text { New Zealand, } \\
\text { Australia }\end{array}$ & $\begin{array}{l}\text { Australian and New Zealand } \\
\text { Intensive Care Research Centre, } \\
\text { Australasian Maternity Outcomes } \\
\text { Surveillance System }\end{array}$ & $\begin{array}{l}64 \text { ICU pregnancy/postpartum } \\
\text { admissions [PCR] }\end{array}$ & ICU admission \\
\hline $\begin{array}{l}\text { Verrall } 2010 \\
{[56]^{*}(8)}\end{array}$ & $\begin{array}{l}\text { June } 8 \text {-August } \\
312009\end{array}$ & $\begin{array}{l}\text { Wellington, } \\
\text { New Zealand }\end{array}$ & $\begin{array}{l}\text { Wellington Hospital and } \\
\text { Hutt Valley Hospitals }\end{array}$ & 229 hospitalizations [rRT-PCR] & Hospitalization \\
\hline $\begin{array}{l}\text { Dee } 2010 \\
\text { [57] (8) }\end{array}$ & $\begin{array}{l}\text { June 17-July } \\
202009\end{array}$ & $\begin{array}{l}\text { Wellington, } \\
\text { New Zealand }\end{array}$ & Hutt Valley Hospital & 54 hospitalizations [RT-PCR] & Hospitalization \\
\hline $\begin{array}{l}\text { Sachedina } \\
2010[58]\end{array}$ & $\begin{array}{l}\text { June } 262009- \\
\text { March } 222010\end{array}$ & England, UK & $\begin{array}{l}\text { Department of Health, Regional } \\
\text { Directors of Public Health, Health } \\
\text { Protection Agency's influenza } \\
\text { reference centers }\end{array}$ & $\begin{array}{l}70 \text { deaths [lab-confirmed } \\
\text { or H1N1 on death certificate] }\end{array}$ & Mortality \\
\hline $\begin{array}{l}\text { Kelly } \\
2011[59]\end{array}$ & $\begin{array}{l}\text { July 1-December } \\
42009\end{array}$ & Australia & $\begin{array}{l}\text { Influenza Complications Alert } \\
\text { Network (FluCAN) sentinel hospitals }\end{array}$ & 465 hospitalizations [rRT-PCR] & Hospitalization, ICU admission \\
\hline $\begin{array}{l}\text { Chien } \\
2010[60]\end{array}$ & $\begin{array}{l}\text { July 2-August } \\
292009\end{array}$ & $\begin{array}{l}\text { Taiwan, } \\
\text { Republic } \\
\text { of China }\end{array}$ & Taiwan CDC & 149 severe illness[RT-PCR] & Pneumonia, respiratory failure \\
\hline
\end{tabular}


Table 1. Cont.

\begin{tabular}{|c|c|c|c|c|c|}
\hline $\begin{array}{l}\text { First author, } \\
\text { Year }\end{array}$ & Time period & $\begin{array}{l}\text { Region of } \\
\text { conduct }\end{array}$ & Data source(s) & $\begin{array}{l}\text { Number of lab-confirmed } \\
\text { H1N1 [confirmation type] }\end{array}$ & Outcome(s) examined \\
\hline $\begin{array}{l}\text { Subramony } \\
2010[61]\end{array}$ & $\begin{array}{l}\text { July } 15- \\
\text { September } \\
282009\end{array}$ & Singapore & $\begin{array}{l}\text { Singapore General Hospital, Tan Tock } \\
\text { Seng Hospital, Alexandra Hospital, } \\
\text { National University Hospital, KK } \\
\text { Women's and Children's Hospital and } \\
\text { Changi General Hospital, Mount } \\
\text { Elizabeth Hospital, Gleneagles Hospital, } \\
\text { Mount Alvernia Hospital, East Shore } \\
\text { Hospital, Thompson Medical Centre } \\
\text { and Raffles Hospital }\end{array}$ & 1348 hospitalizations [RT-PCR] & Hospitalization, severe illness \\
\hline $\begin{array}{l}\text { Satterwhite } \\
2010[62]\end{array}$ & $\begin{array}{l}\text { August 1- } \\
\text { October } \\
312009\end{array}$ & $\begin{array}{l}\text { Atlanta, } \\
\text { Georgia, US }\end{array}$ & $\begin{array}{l}\text { Emory University Hospital, Grady } \\
\text { Memorial Hospital, Emory University } \\
\text { Hospital Midtown/Crawford Long } \\
\text { Hospital, Atlanta Veterans Affairs } \\
\text { Medical Center }\end{array}$ & 109 hospitalizations [PCR] & Hospitalization, ICU admission \\
\hline $\begin{array}{l}\text { Bandaranayake } \\
2011[63]\end{array}$ & $\begin{array}{l}\text { January 1- } \\
\text { Oct } 242010\end{array}$ & New Zealand & $\begin{array}{l}\text { Institute of Environmental Science and } \\
\text { Research, Healthstat, Healthline, Episurv, } \\
\text { National Minimum Data Set, Pandemic } \\
\text { Influenza Mortality Review Committee }\end{array}$ & 1758 [nasopharyngeal swabs] & Hospitalization \\
\hline \multicolumn{6}{|c|}{ LOW-INCOME ECONOMIES OR LOWER-MIDDLE-INCOME ECONOMIES } \\
\hline $\begin{array}{l}\text { Reyes } \\
2010[64]\end{array}$ & $\begin{array}{l}\text { May-December } \\
2009\end{array}$ & Guatemala & $\begin{array}{l}\text { National Hospital of Cuilapa, } \\
\text { Western Regional Hospital, Health } \\
\text { Center of Nueva Santa Rosa }\end{array}$ & 239 [rRT-PCR] & $\begin{array}{l}\text { Hospitalization, ICU admission, } \\
\text { pneumonia, mechanical } \\
\text { ventilation, mortality }\end{array}$ \\
\hline $\begin{array}{l}\text { Louriz } \\
2010[65]\end{array}$ & $\begin{array}{l}\text { June-December } \\
2009\end{array}$ & $\begin{array}{l}\text { Rabat, } \\
\text { Morocco }\end{array}$ & Ibn Sina University Hospital & 186 hospitalizations [RT-PCR] & $\begin{array}{l}\text { Hospitalization, ICU admission, } \\
\text { mechanical ventilation, mortality }\end{array}$ \\
\hline $\begin{array}{l}\text { Lahlou } \\
2011[66]\end{array}$ & $\begin{array}{l}\text { June } 12- \\
\text { December } \\
242009\end{array}$ & $\begin{array}{l}\text { Rabat, } \\
\text { Morocco }\end{array}$ & $\begin{array}{l}\text { Mohammed V Military } \\
\text { Teaching Hospital }\end{array}$ & 240 [rRT-PCR] & $\begin{array}{l}\text { Hospitalization, severe illness, } \\
\text { mortality }\end{array}$ \\
\hline $\begin{array}{l}\text { Jagannatha } \\
\text { Rao } 2011 \text { [67] }\end{array}$ & $\begin{array}{l}\text { August 2009- } \\
\text { April } 2010\end{array}$ & $\begin{array}{l}\text { Karnataka, } \\
\text { India }\end{array}$ & Tertiary care hospital & 20 hospitalizations [rRT-PCR] & $\begin{array}{l}\text { Hospitalization, severe illness, } \\
\text { mortality }\end{array}$ \\
\hline $\begin{array}{l}\text { Chacko } \\
2010[68]\end{array}$ & $\begin{array}{l}\text { August-October } \\
2009\end{array}$ & $\begin{array}{l}\text { Karnataka, } \\
\text { India }\end{array}$ & $\begin{array}{l}\text { Manipal Hospital } \\
\text { multidisciplinary ICU }\end{array}$ & 66 hospitalizations [RT-PCR] & $\begin{array}{l}\text { Hospitalization, ICU admission, } \\
\text { mortality }\end{array}$ \\
\hline $\begin{array}{l}\text { Parakh } \\
2010[69]\end{array}$ & $\begin{array}{l}\text { August 2009- } \\
\text { January } 2010\end{array}$ & $\begin{array}{l}\text { New Delhi, } \\
\text { India }\end{array}$ & Kalawati Saran Children's Hospital & $\begin{array}{l}25 \text { pediatric } \\
\text { hospitalizations [PCR] }\end{array}$ & $\begin{array}{l}\text { Hospitalization, ICU admission, } \\
\text { severe illness, mortality }\end{array}$ \\
\hline $\begin{array}{l}\text { Ramakrishna } \\
2011[70]^{*}(9)\end{array}$ & $\begin{array}{l}\text { August 2009- } \\
\text { October } 2010\end{array}$ & $\begin{array}{l}\text { Tamil Nadu, } \\
\text { India }\end{array}$ & Christian Medical College Hospital & $\begin{array}{l}629 \text { hospitalizations } \\
\text { [rRT-PCR] }\end{array}$ & $\begin{array}{l}\text { Hospitalization, ICU admission, } \\
\text { severe illness mortality }\end{array}$ \\
\hline $\begin{array}{l}\text { Pramanick } \\
2011 \text { [71] (9) }\end{array}$ & $\begin{array}{l}\text { August } 5 \text { 2009- } \\
\text { January } 2010\end{array}$ & $\begin{array}{l}\text { Tamil Nadu, } \\
\text { India }\end{array}$ & Christian Medical College Hospital & 164 [rRT-PCR] & $\begin{array}{l}\text { Hospitalization, ICU admission, } \\
\text { mortality }\end{array}$ \\
\hline $\begin{array}{l}\text { Puvanalingam } \\
2011[72]\end{array}$ & $\begin{array}{l}\text { August } 92009- \\
\text { January } 2010\end{array}$ & $\begin{array}{l}\text { Tamil Nadu, } \\
\text { India }\end{array}$ & $\begin{array}{l}\text { Madras Medical College and } \\
\text { Government General Hospital records, } \\
\text { Institute of Child Health, Egmore }\end{array}$ & $442[\mathrm{RT}-\mathrm{PCR}]$ & $\begin{array}{l}\text { Hospitalization, pneumonia, } \\
\text { mortality }\end{array}$ \\
\hline $\begin{array}{l}\text { Sharma } \\
2010[73]\end{array}$ & $\begin{array}{l}\text { September } 2009 \\
\text { to January } 2010\end{array}$ & Delhi, India & GTB Hospital & $\begin{array}{l}125 \text { hospitalizations } \\
\text { [RT-PCR] }\end{array}$ & $\begin{array}{l}\text { Hospitalization, severe illness, } \\
\text { mortality }\end{array}$ \\
\hline $\begin{array}{l}\text { Chudasama } \\
2011[74]^{*}(10)\end{array}$ & $\begin{array}{l}\text { September 1, } \\
\text { 2009-February } \\
20,2010\end{array}$ & Gujarat, India & $\begin{array}{l}\text { Hospitals in Rajkot city of } \\
\text { Saurashtra region }\end{array}$ & $\begin{array}{l}274 \text { hospitalizations } \\
\text { [rRT-PCR] }\end{array}$ & Hospitalization, mortality \\
\hline $\begin{array}{l}\text { Chudasama } \\
2010[75](10)\end{array}$ & $\begin{array}{l}\text { September } 1, \\
\text { 2009-February } \\
28,2010\end{array}$ & Rajkot, India & $\begin{array}{l}\text { Hospital records, Pediatric Department } \\
\text { of Civil Hospital \& two other pediatric } \\
\text { hospitals of Rajkot city }\end{array}$ & 62 pediatric cases [rRT-PCR] & Hospitalization, mortality \\
\hline $\begin{array}{l}\text { Chudasama } \\
2010 \text { [76] (10) }\end{array}$ & $\begin{array}{l}\text { September } 1 \text {, } \\
\text { 2009-February } \\
20,2010\end{array}$ & Rajkot, India & $\begin{array}{l}\text { Hospitals in Rajkot city of } \\
\text { Saurashtra region }\end{array}$ & 274 hospitalizations [rRT-PCR] & Hospitalization, mortality \\
\hline $\begin{array}{l}\text { Chudasama } \\
2010 \text { [77] (10) }\end{array}$ & $\begin{array}{l}\text { September } 1 \text {, } \\
\text { 2009-February } \\
20,2010\end{array}$ & Rajkot, India & $\begin{array}{l}\text { Hospitals in Rajkot city of } \\
\text { Saurashtra region }\end{array}$ & 274 hospitalizations [rRT-PCR] & Hospitalization, mortality \\
\hline $\begin{array}{l}\text { Chudasama } \\
2010[78](10)\end{array}$ & $\begin{array}{l}\text { September 1, } \\
\text { 2009-January } \\
31,2010\end{array}$ & Rajkot, India & $\begin{array}{l}\text { Hospitals in Rajkot city of } \\
\text { Saurashtra region }\end{array}$ & 274 hospitalizations [rRT-PCR] & Hospitalization, mortality \\
\hline $\begin{array}{l}\text { Gupta } \\
2011[79]\end{array}$ & $\begin{array}{l}\text { November 2009- } \\
\text { February } 2010\end{array}$ & $\begin{array}{l}\text { Rajasthan, } \\
\text { India }\end{array}$ & $\begin{array}{l}\text { Umaid Hospital for } \\
\text { Women and Children }\end{array}$ & $\begin{array}{l}62 \text { pediatric hospitalizations } \\
\text { [rPCR] }\end{array}$ & $\begin{array}{l}\text { Hospitalization, ICU } \\
\text { admission, mortality }\end{array}$ \\
\hline
\end{tabular}


Table 1. Cont.

\begin{tabular}{llllll}
\hline $\begin{array}{l}\text { First author, } \\
\text { Year }\end{array}$ & Time period & $\begin{array}{l}\text { Region of } \\
\text { conduct }\end{array}$ & Data source(s) & $\begin{array}{l}\text { Number of lab-confirmed } \\
\text { H1N1 [confirmation type] }\end{array}$ & Outcome(s) examined \\
\hline Naseem 2011 [80] & $\begin{array}{l}\text { December 1 } \\
2009-M a y ~ 30\end{array}$ & $\begin{array}{l}\text { Rawalpindi, } \\
\text { Pakistan }\end{array}$ & $\begin{array}{l}\text { Department of Pulmonology } \\
\text { and Critical Care, Military } \\
\text { Hospital }\end{array}$ & 36 hospitalizations [RT-PCR] & $\begin{array}{l}\text { Hospitalization, ICU admission, } \\
\text { mechanical ventilation, mortality }\end{array}$ \\
\hline
\end{tabular}

Notes: *major publication, () denotes companion reports.

Abbreviations: CDC Centers for Disease Control, ICU intensive care unit, ILI influenza-like illness, NR not reported, PCR polymerase chain reaction, rRT-PCR real-time reverse transcription-PCR, PH public health, PHAC Public Health Agency of Canada, SES socioeconomic status, UK United Kingdom.

doi:10.1371/journal.pone.0039437.t001

Ten studies reported on obesity [20,30,40,49,65,66,68,70,73,80] and no significant differences were observed with respect to the prevalence of obesity between ethnic minorities and non-ethnic minorities in HIC studies ( $\mathrm{n}=500$ patients, OR $0.76,95 \% \mathrm{CI}$ : 0.46-1.26) [20,30,49]. Four studies reported the proportion of patients who were pregnant and no differences were observed in the odds of being pregnant between ethnic minorities and nonethnic minorities ( $\mathrm{n}=765$ patients, OR $0.31,95 \%$ CI: $0.03-3.64)$ $[30,43,46,49]$. Four studies reported on smoking and alcohol use $[49,72,73,80]$; meta-analysis was not possible because only one study reported on ethnic minorities in a $\mathrm{HIC}$ and the other three were conducted in LIC/LMIC.

\section{Methodological Quality}

The majority of the studies used a sample truly representative of the average individual infected with $\mathrm{H} 1 \mathrm{~N} 1$ in the community (e.g., population-based sample of an entire province or state) or somewhat representative sample of the average individual infected with $\mathrm{H} 1 \mathrm{Nl}$ in the community (e.g., pregnant woman from an entire state or province). Ten studies did not use a representative sample; one included volunteers [45], one included only those with severe illness [33], four included individuals with severe illness who died $[20,29,37,58]$, two included pediatric cases in India [69,79], and two obtained data from one local hospital [43,49] (Table 4). All of the studies selected the non-exposed cohort from the same community as the exposed cohort and used a structured interview (i.e., self-report) to assess exposure (e.g., social disadvantage), except for studies conducted in LIC/LMIC, for which the data were obtained from hospital records. All of the studies ensured that the patients were not severely ill, hospitalized or dead at the start of the study, except for four studies [20,29,37,58]. All studies assessed the outcomes using record linkage, and the duration of follow-up was deemed appropriate in all of the studies. Most studies did not control for important factors, such as comorbidity (13 studies controlled for comorbidities [22,29,32,33,41,43,48,49, $56,58,60,61,63])$ and 18 studies had greater than $10 \%$ of the patients lost to follow-up or did not describe the follow-up rate $[21,22,29,45,48,56,58,60,62,63,65,67-69,72,73,79,80]$.

\section{Hospitalization}

Twenty-four studies reported hospitalization data broken down by ethnicity (Table 2) [24-26,28,30,32,35,38,39,41-47,49,51,52, 56,59,61-63]. Four studies reported the number of H1N1-infected individuals by ethnicity and the prevalence hospitalization among those with $\mathrm{H} 1 \mathrm{Nl}$ ranged from $24-27 \%$ among ethnic minorities and $17-87 \%$ among non-ethnic minorities in HIC [25,38,43,49]. Two studies were not included in the meta-analysis due to concerns about confounding and inclusion of a non-representative sample $[43,49]$. Once these studies were excluded, there was a significantly greater proportion of ethnic minority versus non- ethnic minority hospitalizations ( $\mathrm{n}=1,313$ patients, OR $2.26,95 \%$ CI: $1.53-3.32, I^{2}=28 \%$; Figure 2) [25,36]. Similarly, a study including pregnant women infected with $\mathrm{H} 1 \mathrm{Nl}$ reported a significantly higher proportion of hospitalizations among ethnic minorities $(72 \%)$ versus non-ethnic minorities $(53 \%$; OR based on this study: 2.27, 95\% CI: 1.57-3.28) [28].

All of the studies conducted in LIC/LMIC reported hospitalization data for individuals with $\mathrm{H} 1 \mathrm{Nl}$ (Table 3). The prevalence of hospitalization among those infected with $\mathrm{H} 1 \mathrm{~N} 1$ was $32 \%$ in Guatemala [64], 11\% in Morocco [66], and 45\% in India [72]. Prevalence meta-analysis was not possible because only one study was conducted in each country.

\section{Severe IIIness}

Nineteen of the included studies reported the number of $\mathrm{H} 1 \mathrm{Nl}$ patients experiencing severe illness broken down by ethnicity, including intensive care unit (ICU) admission [19,21,25,26, $28,30,33,35,43,44,48,49,51-53,59,62]$, severe illness unspecified [61], and pneumonia or respiratory failure [60]. One study of H1N1-infected pregnant women observed similar proportions of ICU admissions between ethnic minorities (15\%) and non-ethnic minorities (19\%; OR based on this study: 0.74 , 95\% CI: $0.46-$ 1.20) [28]. One study observed a similar relationship for patients admitted to the ICU among all $\mathrm{H} 1 \mathrm{Nl}$-infected patients in Australia (OR 0.24, 95\% CI: 0.05-1.20) [43], while another study observed a greater proportion of ICU admissions among ethnic minorities in Manitoba (OR 2.76, 95\% CI: 1.45-5.23) [25]. Metaanalysis was not conducted because the Australian study was affected by confounding and did not use a representative sample [43]. In LIC/LMIC, the proportion of ICU admissions among $\mathrm{H} 1 \mathrm{~N} 1$-infected was $9 \%$ in Guatemala [64] and $0 \%$ in Morocco [66].

One study of H1N1-infected pregnant women observed a significantly greater proportion of ICU admissions among nonethnic minority hospitalizations $(35 \%)$ versus ethnic minority hospitalizations (35\%; OR based on this study: $0.47,95 \%$ CI: 0.28-0.79) [28]. Eight studies reported ethnicity data on the proportion of patients admitted to the ICU among those hospitalized in $\mathrm{HIC}$ and were meta-analyzed [25,26,30,35,44, 51,59,62]. The prevalence ranged from 6-68\% among ethnic minorities and $7-76 \%$ among non-ethnic minorities. One study was not included in the meta-analysis due to concerns about confounding and inclusion of a non-representative sample [43]. Excluding this study, there were no differences in ICU admissions among hospitalized non-ethnic minorities compared to ethnic minorities $(\mathrm{n}=15,352$ patients, OR 0.84, 95\% CI: 0.69, 1.02, $\mathrm{I}^{2}=51 \%$, Figure 3$)$.

All of the studies conducted in LIC/LMIC reported data on severe illness (Table 3). Two studies conducted in India reported ICU admission among hospitalized adults and the pooled 


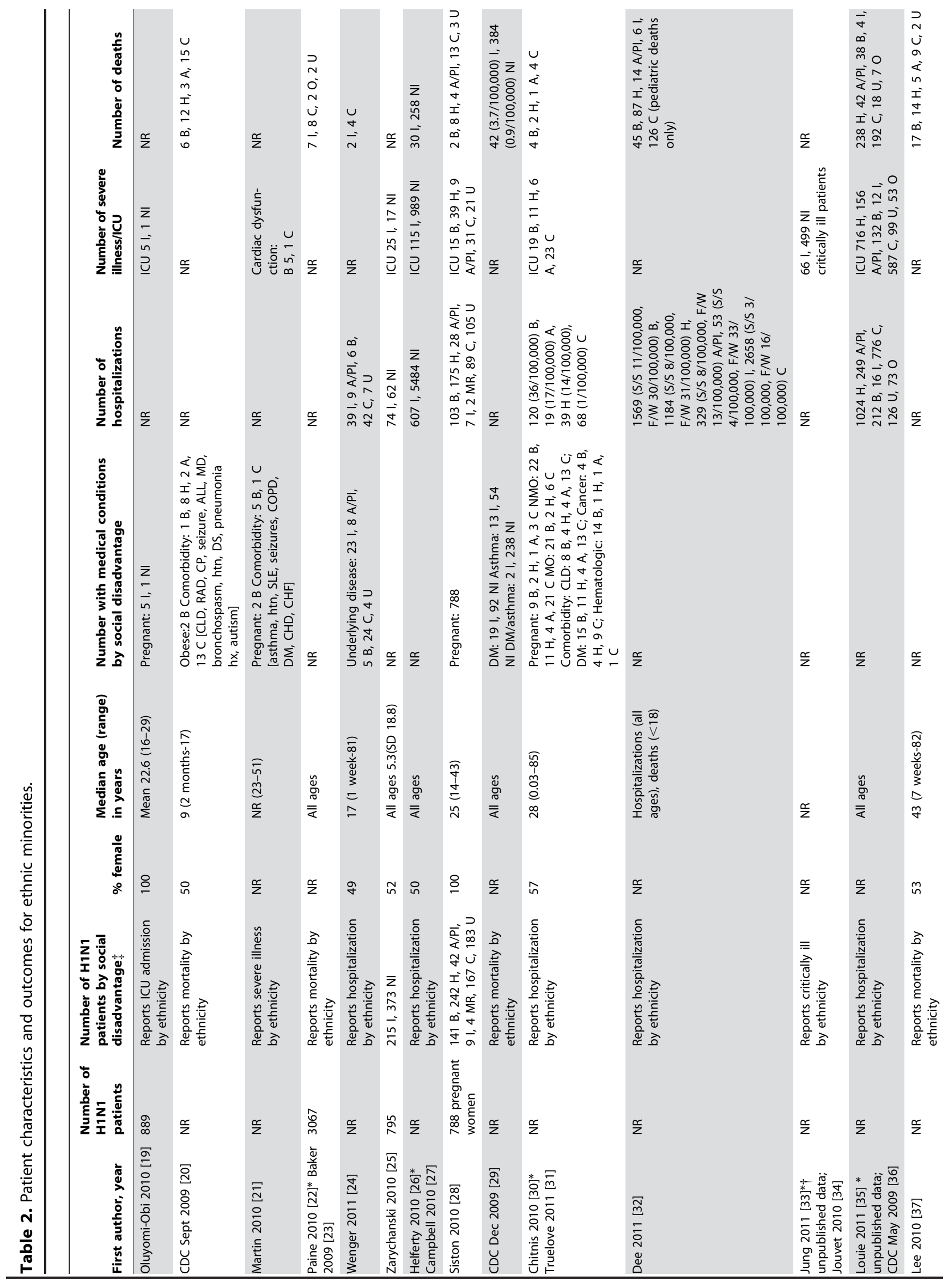



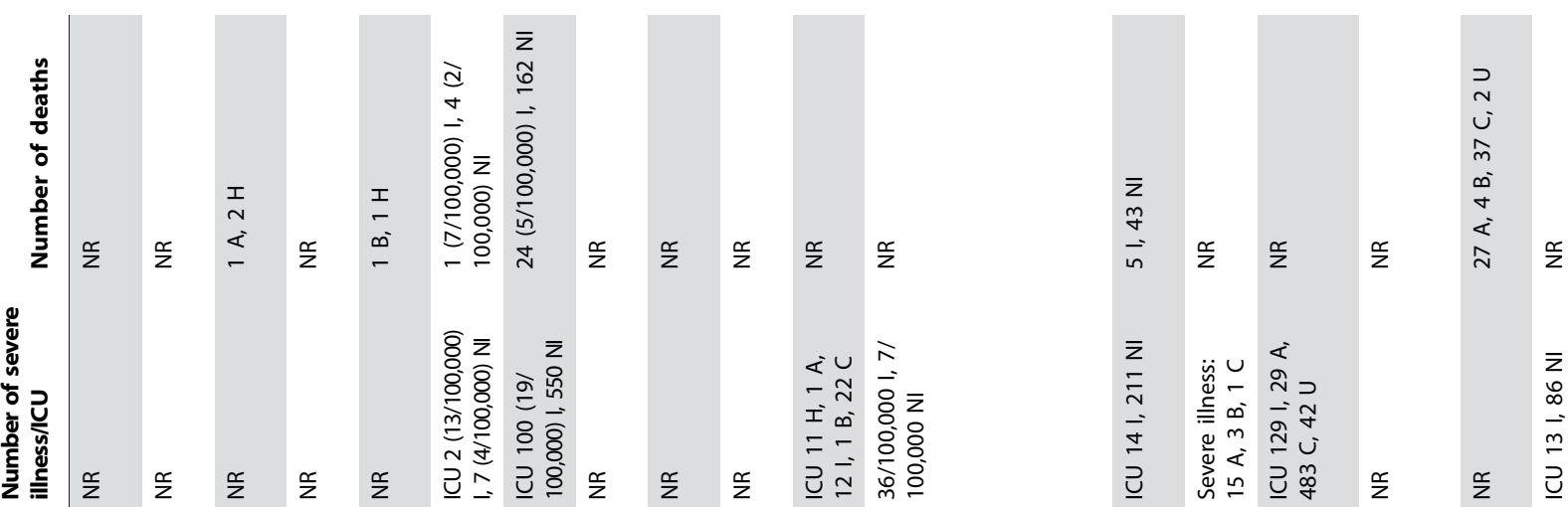

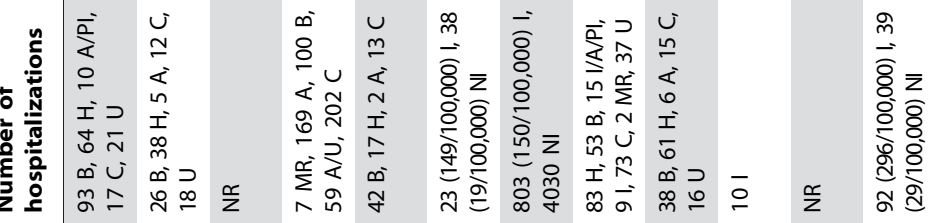
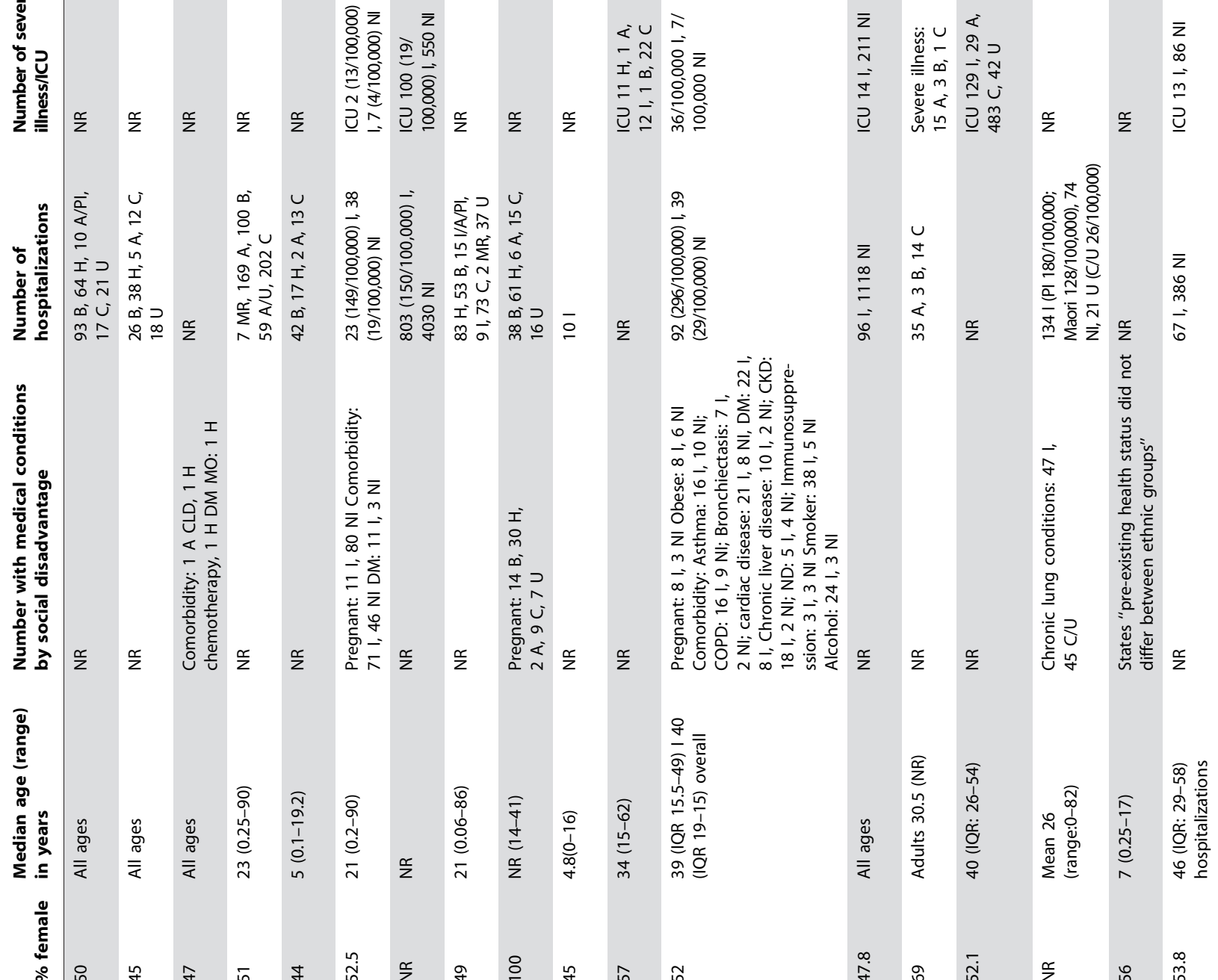

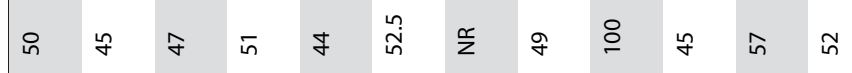
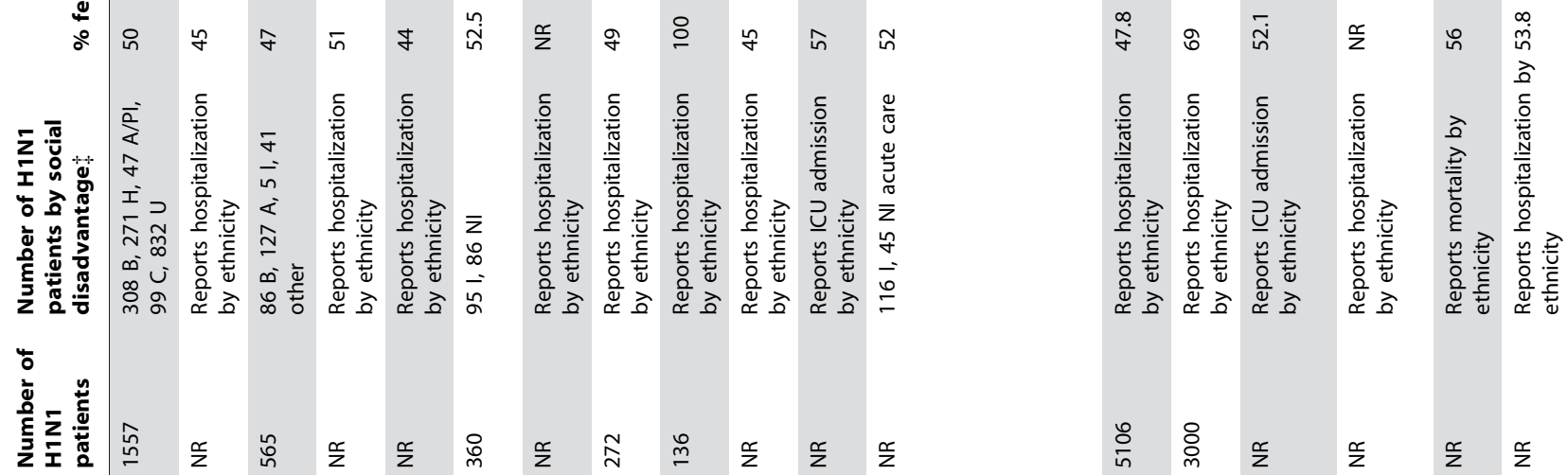

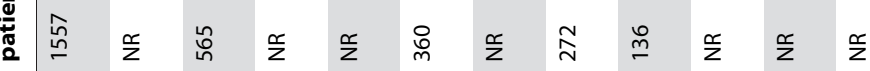

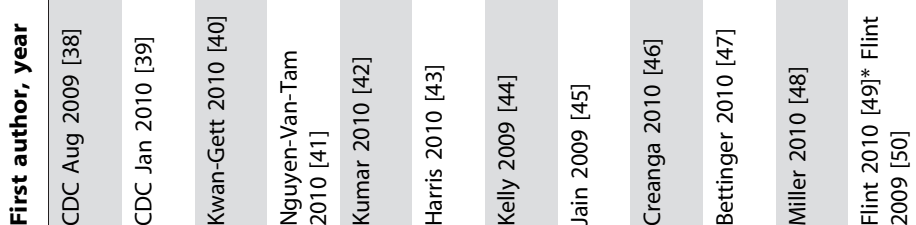

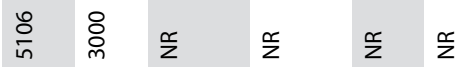


H1N1 Burden among Socially Disadvantaged Groups

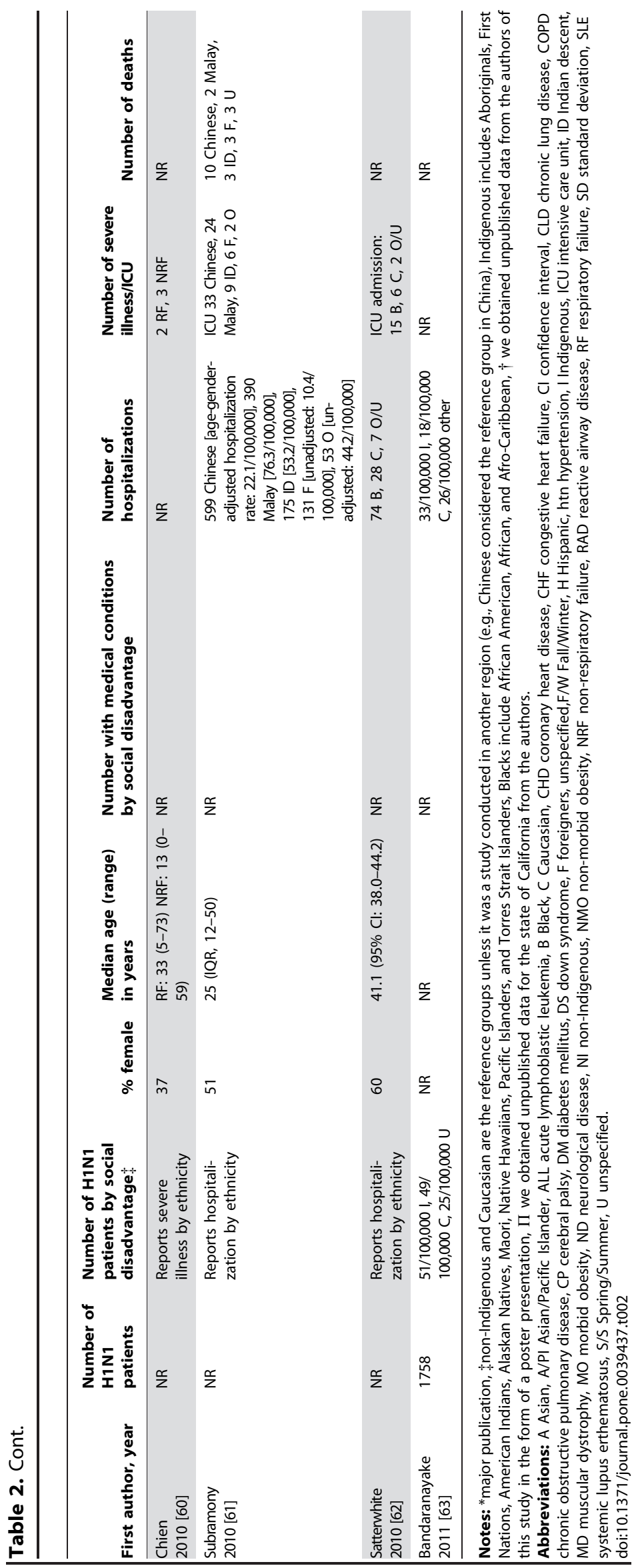




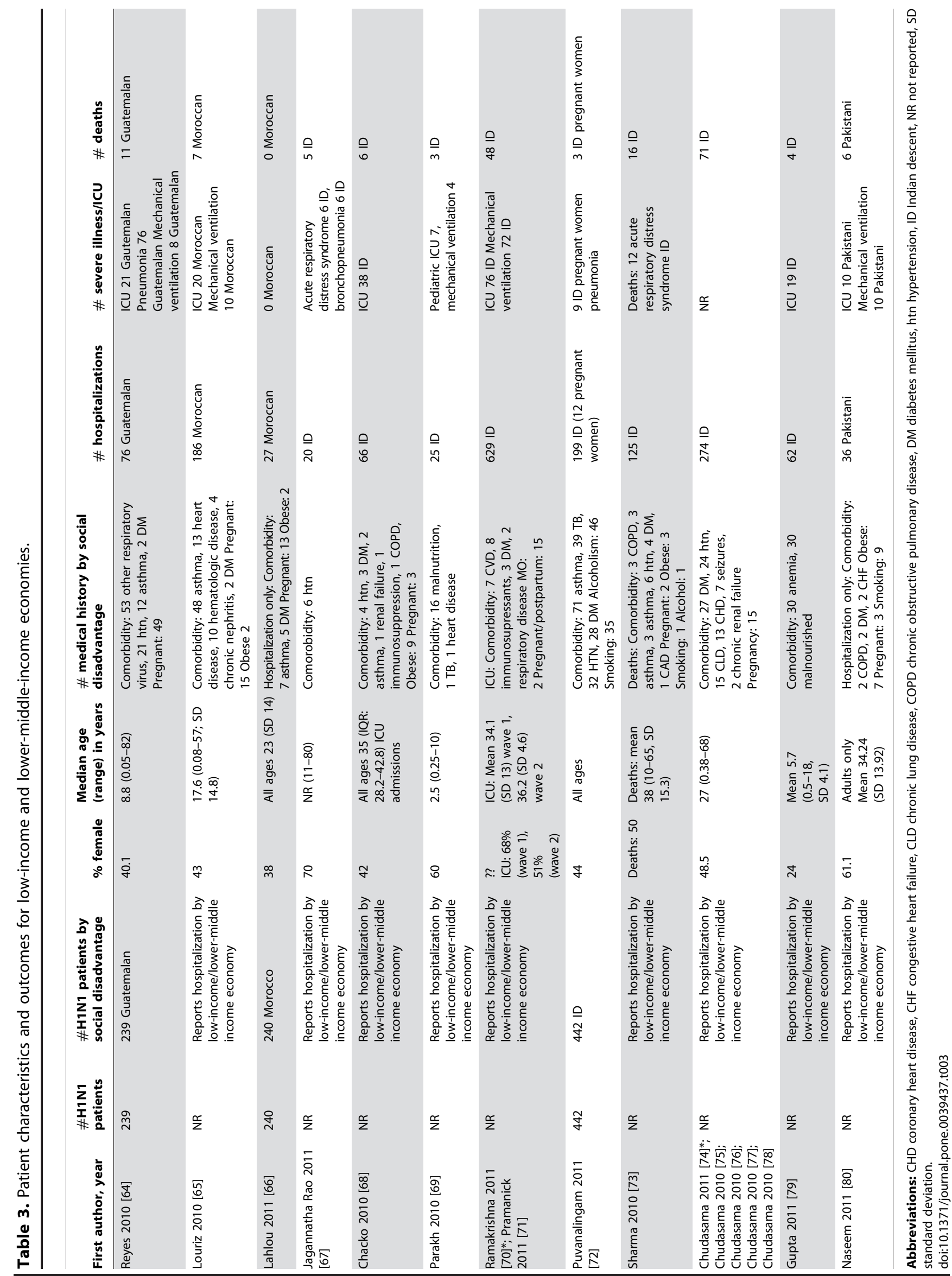




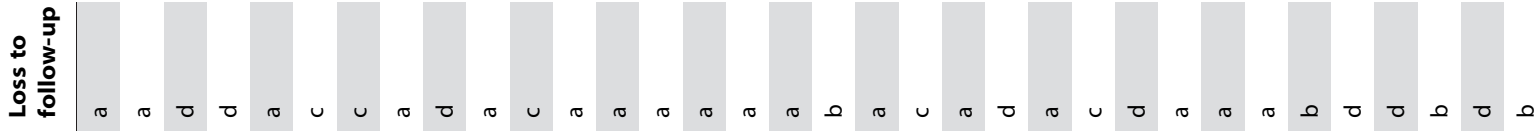

$\ddot{y}$

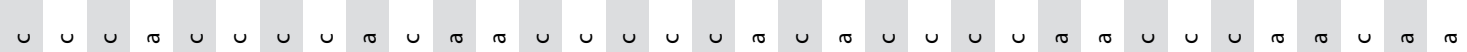




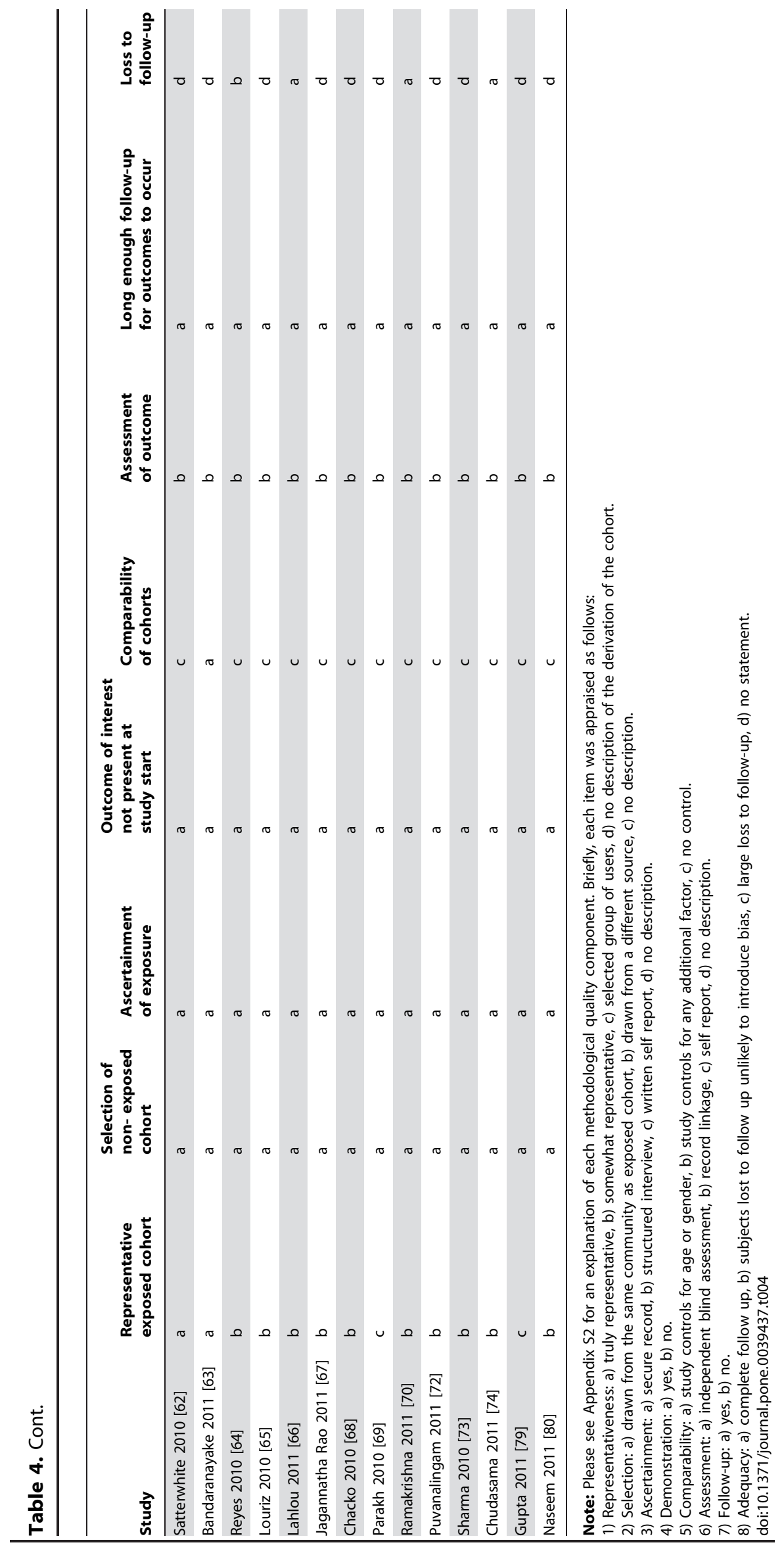




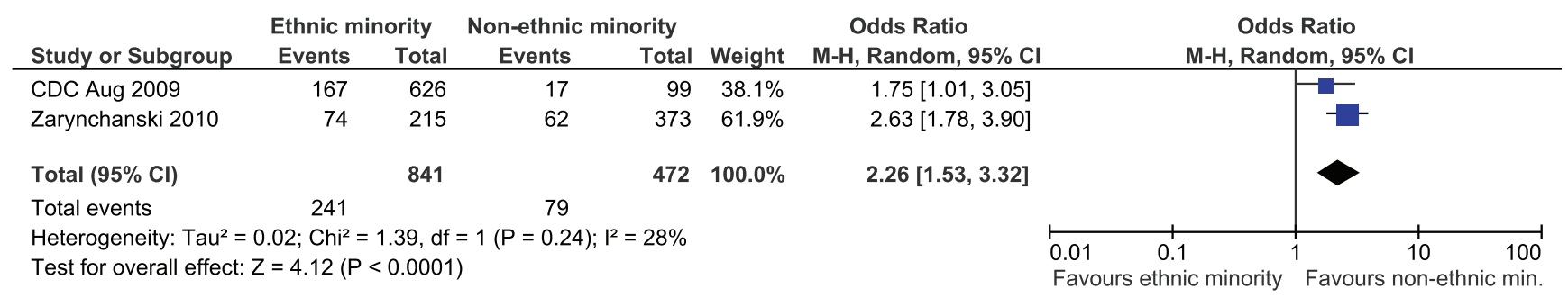

Figure 2. Meta-analysis of hospitalizations among ethnic minorities versus non-ethnic minorities in North America. Favours ethnic minority means that ethnic minorities experienced a lower proportion of H1N1 hospitalizations compared to non-ethnic minorities. Favours nonethnic minorities means that non-ethnic minorities experienced a lower proportion of H1N1 hospitalizations compared to ethnic minorities. doi:10.1371/journal.pone.0039437.g002

prevalence was 34\% (95\% CI: $0-79 \%)$ [68,70]. Two studies reported this information among Indian children and the pooled prevalence was $30 \%$ (95\% CI: $20-40 \%$ ) [69,79].

\section{Mortality}

Fifteen studies reported the number of deaths by ethnicity $[20,22,24,26,29,30,32,33,35,37,40,43,44,51,58]$. One study of pregnant women infected with $\mathrm{H} 1 \mathrm{Nl}$ observed a significantly lower proportion of deaths among H1N1-infected pregnant ethnic minorities $(3 \%)$ versus pregnant non-ethnic minorities $(15 \%$; OR based on this study: $0.19,95 \%$ CI: $0.09-0.43$ ) [28]. None of the others reported the proportion of deaths among H1N1-infected individuals. This study also observed a significantly lower death rate among pregnant ethnic minority hospitalizations (4\%) versus pregnant non-ethnic minority hospitalizations (15\%; OR 0.27 , 95\% CI: $0.12-0.61$ ) [28]. Mortality ranged from 1-21\% among ethnic minorities and 4-25\% among non-ethnic minorities in HIC. Six studies reported the proportion of deaths among hospitalized patients and were meta-analyzed [24,26,30,35, $44,51]$. One study was not included in the meta-analysis due to confounding and inclusion of a non-representative sample [43]. Excluding this study, there were no differences in the proportion of deaths among hospitalized non-ethnic minorities compared to ethnic minorities $(\mathrm{n}=14,757$ patients, OR 0.85 , 95\% CI: $0.73-$ $1.01, \mathrm{I}^{2}=0 \%$, Figure 4$)$.

All of the studies conducted in LIC/LMIC reported mortality (Table 3). Five studies conducted in India reported the number of deaths among hospitalized adults and the pooled prevalence was
$15 \% \quad(95 \%$ CI: $7-23 \%) \quad[67,68,70,73,74]$. Two reported this information among Indian children and the pooled prevalence was 8\% (95\% CI: $2-13 \%)$ [69,79].

\section{Discussion}

We conducted a systematic review on the occurrence of hospitalization, severe illness, and mortality among socially disadvantaged groups of the population. The prevalence of hospitalization among those with $\mathrm{H} 1 \mathrm{~N} 1$ ranged from $24-27 \%$ among ethnic minorities and $17-87 \%$ among non-ethnic minorities in HIC and was $11-45 \%$ in LIC/LMIC. The proportion of patients admitted to the ICU among those with $\mathrm{H} 1 \mathrm{~N} 1$ ranged from 2-12\% among ethnic minorities and 5-8\% among nonethnic minorities in HIC and was $0-9 \%$ in LIC/LMIC. The proportion of ICU admissions among hospitalized patients ranged from $6-68 \%$ among ethnic minorities and 7-76\% among nonethnic minorities in HIC. The pooled prevalence of ICU admission among hospitalizations in India was approximately $30 \%$. The prevalence of mortality ranged from $1-21 \%$ among ethnic minorities and 4-25\% among non-ethnic minorities in HIC and the pooled prevalence of deaths among hospitalizations ranged from $8-15 \%$ in India. These estimates suggest that the burden of H1N1 was significant across LIC/LMIC and HIC.

Our results are similar to previous reviews on the global burden of H1N1. In a systematic review of $\mathrm{H} 1 \mathrm{Nl}$ in the Southern Hemisphere, $17-45 \%$ of laboratory-confirmed $\mathrm{H} 1 \mathrm{~N} 1$ cases were hospitalized, of which 8-26\% were admitted to ICUs and $14-22 \%$ died [5]. A similar burden was observed in the Northern

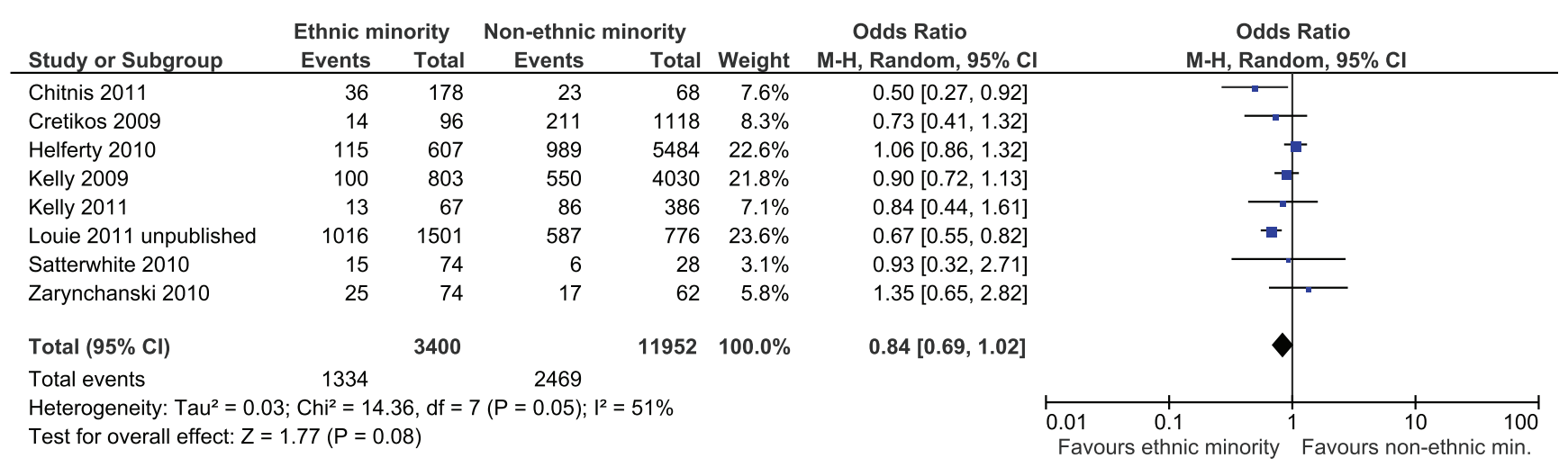

Figure 3. Meta-analysis of ICU admissions among ethnic minorities versus non-ethnic minorities. Favours ethnic minority means that ethnic minorities experienced a lower proportion of intensive care unit (ICU) admissions due to H1N1 compared to non-ethnic minorities. Favours non-ethnic minorities means that non-ethnic minorities experienced a lower proportion of ICU admissions due to H1N1 compared to ethnic minorities.

doi:10.1371/journal.pone.0039437.g003 


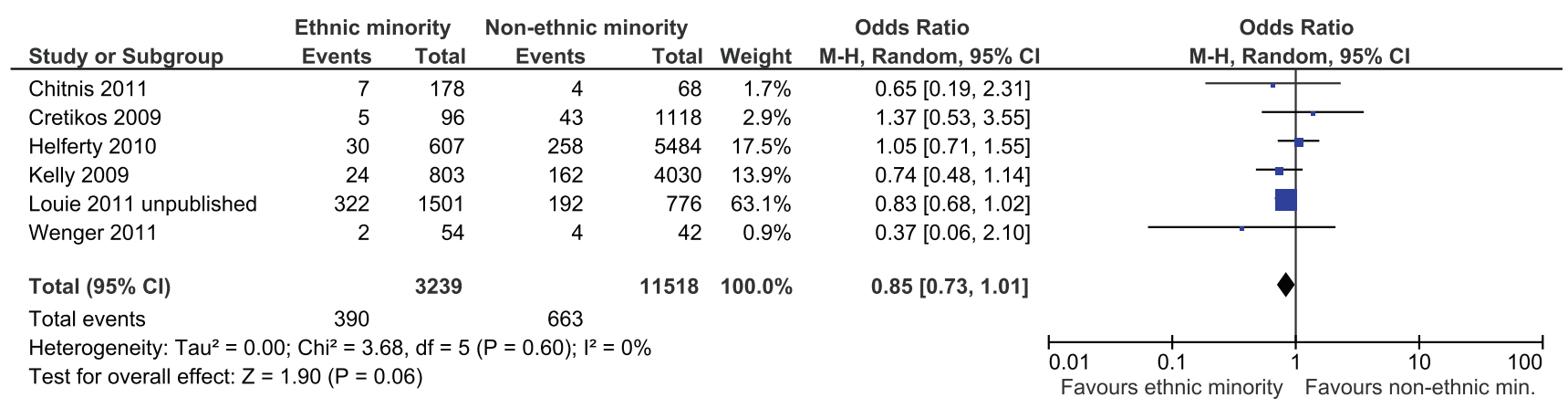

Figure 4. Meta-analysis of mortality among hospitalized ethnic minorities versus hospitalized non-ethnic minorities. Favours ethnic minority means that ethnic minorities experienced a lower proportion of deaths due to H1N1 among hospitalized patients compared to non-ethnic minorities. Favours non-ethnic minorities means that non-ethnic minorities experienced a lower proportion of deaths due to H1N1 among hospitalized patients compared to ethnic minorities. doi:10.1371/journal.pone.0039437.g004

Hemisphere, with $94 \%$ of patients hospitalized, $36 \%$ of patients admitted to ICU, and 39\% died [6]. The current review is more comprehensive, with a scope encompassing all regions of the world and comparisons drawn across ethnic minorities in $\mathrm{HIC}$ and individuals from LIC/LMIC.

Another study pooled data on risk factors for acquiring $\mathrm{H} 1 \mathrm{~N} 1$ pandemic and included data from governmental surveillance programs across 19 countries [81]. In this study, ethnic minorities had a higher risk of hospitalization and fatality compared to the general population in Canada, Australia, and New Zealand. For severe $\mathrm{H} 1 \mathrm{~N} 1$ pandemic, ethnic minorities were under-represented among cases in Thailand and Mexico [81]. Meta-analysis results were not reported due to the small number of countries reporting data.

Some of the included studies compared the burden of $\mathrm{H} 1 \mathrm{~N} 1$ for ethnic minorities versus non-ethnic minorities in HIC, allowing comparisons between these groups. In two large North American studies, there were significantly more hospitalizations among ethnic minorities versus non-ethnic minorities [25,38]. However, there were no differences in ICU admissions or deaths among patients hospitalized with $\mathrm{H} 1 \mathrm{~N} 1$ for ethnic minorities and nonethnic minorities among studies conducted in North America and Australia. It is possible that non-ethnic minorities had a greater proportion of comorbidities, pregnancy or obesity - known risk factors for pandemic $\mathrm{HlNl}$ (i.e., confounding variables) $[5,6]$. However, we did not find any differences in these factors between ethnic minorities and non-ethnic minorities in HIC across some of the studies that were included in the meta-analyses.

Pregnancy is a recognized risk factor for seasonal influenza and pandemic influenza $[5,6,82]$. One of the studies included pregnant women infected with $\mathrm{H} 1 \mathrm{Nl}$ and the results were inconsistent across the outcomes examined [28]. For example, significantly higher hospitalizations were observed for pregnant ethnic minorities versus pregnant non-ethnic minorities, yet a significantly higher proportion of deaths occurred among pregnant non-ethnic minorities versus pregnant ethnic minorities [28]. These results could be because non-ethnic minorities had a greater proportion of comorbidity, but this information was not reported. Only one study reported this data so we were unable to examine pregnancy further through meta-analysis.

A small number of seniors were infected with the pandemic A/ $\mathrm{H} 1 \mathrm{N1} / 2009$ virus, which is inconsistent with previous influenza pandemics [5]. This is likely because seniors were previously exposed to a similar H1N1 strain [83], affording some protection against the 2009 pandemic. However, the elderly still experienced high hospitalization and death rates [5,6]. We were unable to examine this as none of the included studies reported data specific to elderly socially disadvantaged individuals.

There are limitations associated with the conduct of our systematic review. First, we were unable to include some studies if they did not provide a breakdown for the outcomes of interest by ethnicity. Furthermore, we found that because the classification of ethnicity varies by region, drawing comparisons across countries was difficult [84]. Second, some potentially relevant studies were excluded if they did not isolate confirmed cases from suspected cases in their analysis. Third, some of the included studies did not report details, such as total number of individuals with $\mathrm{H} 1 \mathrm{~N} 1$, record of potential confounding variables or number lost to followup. For these reasons, the systematic review conduct was challenging.

It is possible that relevant unpublished studies were omitted, although efforts were made to contact authors and request access to data that had been presented at conferences. Through these efforts, we successfully obtained the results from two unpublished studies [33,35]. As well, it's worth noting that due to the small number of studies included in the meta-analysis of $\mathrm{HIC}$, we were unable to assess the impact of publication bias on our results (i.e., through the use of a funnel plot). Finally, our results are generalizable only to ethnic-minorities in $\mathrm{HIC}$ and individuals in LIC/LMIC, as none of the identified studies reported data for other types of social disadvantage (e.g., groups without access or disproportionate access to healthcare or individuals of low socioeconomic status).

To conclude, the prevalence of hospitalization, severe illness, and mortality due to $\mathrm{H} 1 \mathrm{~N} 1$ was high for ethnic minorities in $\mathrm{HIC}$ and individuals from LIC/LMIC. In addition, there was an increased proportion of hospitalization among ethnic minorities compared to non-ethnic minorities in two studies conducted in North America. However, a similar risk of ICU admission and death was observed among ethnic minorities and non-ethnic minorities in studies conducted in Canada, the United States, and Australia. These results suggest that there was little difference in H1Nl burden between ethnic minorities and non-ethnic minorities living in HIC.

\section{Supporting Information}

Appendix S1 Medline search strategy. (DOCX)

Appendix S2 Methodological quality. 
(DOCX)

Appendix S3 Confounding variables and meta-analysis results. (DOCX)

\section{Flowchart S1 \\ (DOCX)}

\section{Ghecklist S1}

(DOCX)

\section{Acknowledgments}

We thank Nahoko Shindo of the WHO and Tanya Horsley for providing us with potentially relevant articles. We also thank Janice Louie and

\section{References}

1. Reed C, Angulo FJ, Swerdlow DL, Lipsitch M, Meltzer MI, et al. (2009) Estimates of the prevalence of pandemic (H1N1) 2009, United States, April-July 2009. Emerg Infect Dis 15: 2004-2007.

2. Galante M, Garin O, Sicuri E, Cots F, Garcia-Altes A, et al. (2012) Health Services Utilization, Work Absenteeism and Costs of Pandemic Influenza A (H1N1) 2009 in Spain: A Multicenter-Longitudinal Study. PLoS One 7: e31696.

3. Lai PL, Panatto D, Ansaldi F, Canepa P, Amicizia D, et al. (2011) Burden of the 1999-2008 seasonal influenza epidemics in Italy: comparison with the H1N1v (A/California/07/09) pandemic. Hum Vaccin 7 Suppl: 217-225.

4. Higgins AM, Pettila V, Harris AH, Bailey M, Lipman J, et al. (2011) The critical care costs of the influenza A/H1N1 2009 pandemic in Australia and New Zealand. Anaesth Intensive Care 39: 384-391.

5. Falagas ME, Koletsi PK, Baskouta E, Rafailidis PI, Dimopoulos G, et al. (2011) Pandemic A(H1N1) 2009 influenza: review of the Southern Hemisphere experience. Epidemiol Infect 139: 27-40.

6. Falagas ME, Cholevas NV, Kapaskelis AM, Vouloumanou EK, Michalopoulos A, et al. (2010) Epidemiological aspects of 2009 H1N1 influenza: the accumulating experience from the Northern Hemisphere. Eur J Clin Microbiol Infect Dis 29: 1327-1347.

7. Larussa P (2011) Pandemic Novel 2009 H1N1 Influenza: What Have We Learned? Semin Respir Crit Care Med 32: 393-399.

8. Moher D, Liberati A, Tetzlaff J, Altman DG (2009) Preferred reporting items for systematic reviews and meta-analyses: the PRISMA statement. BMJ 339: b2535.

9. La Ruche G, Tarantola A, Barboza P, Vaillant L, Gueguen J, et al. (2009) The 2009 pandemic H1N1 influenza and indigenous populations of the Americas and the Pacific. Euro Surveill 14.

10. Center for Disease Control and Prevention (CDC) (2009) Evaluation of rapid influenza diagnostic tests for detection of novel influenza A (H1N1) Virus United States. MMWR Morb Mortal Wkly Rep 58: 826-829.

11. Landry ML (2011) Diagnostic tests for influenza infection. Curr Opin Pediatr 23: $91-97$.

12. Centers for Disease Control and Prevention (CDC) (2011) Influenza Diagnostic Testing Algorithm. Available: http://www.cdc.gov/flu/professionals/diagnosis/ testing_algorithm.htm. Accessed Sept 14, 2011.

13. World Bank (2011) World Bank Classification. Available: http://data. worldbank.org/about/country-classification/country-and-lending-groups. Accessed Sept 14, 2011.

14. Galarce EM, Minsky S, Viswanath K (2011) Socioeconomic status, demographics, beliefs and $\mathrm{A}(\mathrm{H} 1 \mathrm{~N} 1)$ vaccine uptake in the United States. Vaccine 29: 5284 5289.

15. Wells G, Shea BJ, O’Connell D, Peterson J, Welch V, et al. (2011) The Newcastle-Ottawa Scale (NOS) for assessing the quality of nonrandomised studies in meta-analyses. Available: http://www.ohri.ca/programs/clinical_ epidemiology/oxford.asp. Accessed Sept 14, 2011.

16. DerSimonian R, Laird N (1986) Meta-analysis in clinical trials. Control Clin Trials 7: 177-188.

17. Higgins JP, Thompson SG (2002) Quantifying heterogeneity in a meta-analysis. Stat Med 21: 1539-1558.

18. Cochrane Handbook for Systematic Reviews of Interventions Version 5.0.2 (2009) [updated September 2009]. The Cochrane Collaboration. Available: www.cochrane-handbook.org. Accessed Sept 14, 2011.

19. Oluyomi-Obi T, Avery L, Schneider C, Kumar A, Lapinsky S, et al. (2010) Perinatal and maternal outcomes in critically ill obstetrics patients with pandemic H1N1 Influenza A. J Obstet Gynaecol Can 32: 443-447.

20. Centers for Disease Control and Prevention (CDC) (2009) Surveillance for Pediatric Deaths Associated with 2009 Pandemic Influenza A (H1N1) Virus Infection -- United States, April-August 2009. MMWR Morb Mortal Wkly Rep 58: 941-947.

21. Martin SS, Hollingsworth CL, Norfolk SG, Wolfe CR, Hollingsworth JW (2010) Reversible cardiac dysfunction associated with pandemic 2009 influenza A(H1N1). Chest 137: 1195-1197.

22. Paine S, Mercer GN, Kelly PM, Bandaranayake D, Baker MG, et al. (2010) Transmissibility of 2009 pandemic influenza A(H1N1) in New Zealand: effective
Samuel Yang for providing unpublished data from the state of California and Anand Kumar for sharing their poster presentation. We thank Maggie Chen for her statistical consultation and for meta-analyzing the prevalence estimates from India.

\section{Author Contributions}

Conceived and designed the experiments: ACT SES. Performed the experiments: EL CS LP ACT. Analyzed the data: ACT SES. Wrote the paper: ACT EL CS LP SES. reproduction number and influence of age, ethnicity and importations. Euro Surveill 15.

23. Baker MG, Wilson N, Huang QS, Paine S, Lopez L, et al. (2009) Pandemic influenza A(H1N1)v in New Zealand: the experience from April to August 2009. Euro Surveillance: Bulletin Europeen sur les Maladies Transmissibles = European Communicable Disease Bulletin 14.

24. Wenger JD, Castrodale LJ, Bruden DL, Keck JW, Zulz T, et al. (2011) 2009 Pandemic influenza A H1N1 in Alaska: temporal and geographic characteristics of spread and increased risk of hospitalization among Alaska Native and Asian/ Pacific Islander people. Clin Infect Dis 52: S189-S197.

25. Zarychanski R, Stuart TL, Kumar A, Doucette S, Elliott L, et al. (2010) Correlates of severe disease in patients with 2009 pandemic influenza (H1N1) virus infection. CMAJ 182: 257-264.

26. Helferty M, Vachon J, Tarasuk J, Rodin R, Spika J, et al. (2010) Incidence of hospital admissions and severe outcomes during the first and second waves of pandemic (H1N1) 2009. CMAJ 182: 1981-1987.

27. Campbell A, Rodin R, Kropp R, Mao Y, Hong Z, et al. (2010) Risk of severe outcomes among patients admitted to hospital with pandemic (H1N1) influenza. CMAJ 182: 349-355.

28. Siston AM, Rasmussen SA, Honein MA, Fry AM, Seib K, et al. (2010) Pandemic 2009 influenza $\mathrm{A}(\mathrm{H} 1 \mathrm{~N} 1)$ virus illness among pregnant women in the United States. JAMA 303: 1517-1525.

29. Centers for Disease Control and Prevention (CDC) (2009) Deaths related to 2009 pandemic influenza A (H1Nl) among American Indian/Alaska Natives 12 states, 2009. MMWR Morb Mortal Wkly Rep 58: 1341-1344.

30. Chitnis AS, Truelove SA, Druckenmiller JK, Heffernan RT, Davis JP (2010) Epidemiologic and clinical features among patients hospitalized in Wisconsin with $2009 \mathrm{H} 1 \mathrm{Nl}$ influenza A virus infections, april to august 2009. Wis Med J 109: 201-208

31. Truelove SA, Chitnis AS, Heffernan RT, Karon AE, Haupt TE, et al. (2011) Comparison of patients hospitalized with pandemic 2009 influenza A (H1N1) virus infection during the first two pandemic waves in Wisconsin. J Infect Dis 203: 828-837.

32. Dee DL, Bensyl DM, Gindler J, Truman BI, Allen BG, et al. (2011) Racial and Ethnic Disparities in Hospitalizations and Deaths Associated with 2009 Pandemic Influenza A (H1N1) Virus Infections in the United States. Ann Epidemiol 21: 623-630.

33. Jung J, Fowler R, Long J, Zarychanski R, Rodin R, et al. (2011) 2009-2010 H1N1-related critical illness among Aboriginal and Non-Aboriginal Canadians. Unpublished data.

34. Jouvet P, Hutchison J, Pinto R, Menon K, Rodin R, et al. (2010) Critical illness in children with influenza A/pH1N1 2009 infection in Canada. Pediatr Crit Care Med 11: 603-609.

35. Louie J, Yang S (2011) Hospitalizations with 2009 novel influenza A(H1N1) in California. Unpublished data.

36. Centers for Disease Control and Prevention (CDC) (2009) Hospitalized Patients with Novel Influenza A (H1N1) Virus Infection -- California, April-May, 2009. MMWR Morb Mortal Wkly Rep 58: 536-541.

37. Lee EH, Wu C, Lee EU, Stoute A, Hanson H, et al. (2010) Fatalities associated with the 2009 H1N1 influenza A virus in New York city. Clin Infect Dis 50: 1498-1504.

38. Centers for Disease Control and Prevention (CDC) (2009) 2009 Pandemic Influenza A (H1N1) Virus Infections -- Chicago, Illinois, April-July 2009. MMWR Morb Mortal Wkly Rep 58: 913-918.

39. Centers for Disease Control and Prevention (CDC) (2010) Patients hospitalized with 2009 pandemic influenza A (H1N1) - New York City, May 2009. MMWR Morb Mortal Wkly Rep 58: 1436-1440.

40. Kwan-Gett TS, Baer A, Duchin JS (2009) Spring 2009 H1N1 influenza outbreak in King County, Washington. Disaster Med Public Health Prep 3: S109-S116.

41. Nguyen-Van-Tam JS, Openshaw P, Hashim A, Gadd EM, Lim WS, et al. (2010) Risk factors for hospitalisation and poor outcome with pandemic A/ H1N1 influenza: United Kingdom first wave (May-September 2009). Thorax 65: 645-651. 
42. Kumar S, Havens PL, Chusid MJ, Willoughby RE, Simpson P, et al. (2010) Clinical and epidemiologic characteristics of children hospitalized with 2009 pandemic H1N1 influenza A infection. Pediatr Infect Dis J 29: 591-594.

43. Harris PN, Dixit R, Francis F, Buettner PG, Leahy C, et al. (2010) Pandemic influenza H1N1 2009 in north Queensland-risk factors for admission in a region with a large indigenous population. Commun Dis Intell 34: 102-109.

44. Kelly H, Mercer G, Cheng A (2009) Quantifying the risk of pandemic influenza in pregnancy and indigenous people in Australia in 2009. Euro Surveillance: Bulletin Europeen sur les Maladies Transmissibles = European Communicable Disease Bulletin 14.

45. Jain S, Kamimoto L, Bramley AM, Schmitz AM, Benoit SR, et al. (2009) Hospitalized patients with $2009 \mathrm{H} 1 \mathrm{Nl}$ influenza in the United States, April-June 2009. N Engl J Med 361: 1935-1944.

46. Creanga AA, Johnson TF, Graitcer SB, Hartman LK, Al-Samarrai T, et al. (2010) Severity of 2009 pandemic influenza A (H1N1) virus infection in pregnant women. Obstet Gynecol 115: 717-726.

47. Bettinger JA, Sauve LJ, Scheifele DW, Moore D, Vaudry W, et al. (2010) Pandemic influenza in Canadian children: a summary of hospitalized pediatric cases. Vaccine 28: 3180-3184.

48. Miller RR, Markewitz BA, Rolfs RT, Brown SM, Dascomb KK, et al. (2010) Clinical findings and demographic factors associated with ICU admission in Utah due to novel 2009 influenza A(H1N1) infection. Chest 137: 752-758.

49. Flint SM, Davis JS, Su JY, Oliver-Landry EP, Rogers BA, et al. (2010) Disproportionate impact of pandemic (H1N1) 2009 influenza on Indigenous people in the Top End of Australia's Northern Territory. Med J Aust 192: 617622 .

50. Flint SM, Su JY, Scott L, Krause V (2009) The early experience of pandemic (H1N1) 2009 influenza in Northern Territory, Australia. The Northern Territory Disease Control Bulletin 16: 1-8.

51. Cretikos M, Muscatello DJ, Patterson J, Conaty S, Churches T, et al. (2009) Progression and impact of the first winter wave of the 2009 pandemic H1N1 influenza in New South Wales, Australia. Euro Surveill 14.

52. Scriven J, Mcewen R, Mistry S, Green C, Osman H, et al. (2009) Swine flu: a Birmingham experience. Clin Med 9: 534-538.

53. Webb SA, Pettila V, Seppelt I, Bellomo R, Bailey M, et al. (2009) Critical care services and $2009 \mathrm{H} 1 \mathrm{Nl}$ influenza in Australia and New Zealand. N Engl J Med 361: 1925-1934

54. Knight MP (2011) Critical illness with AH1N1v influenza in pregnancy: a comparison of two population-based cohorts. BJOG 118: 232-239.

55. Australian and New Zealand Intensive Care (ANZIC) Influenza Investigators (2010) Critical illness due to $2009 \mathrm{~A} / \mathrm{H} 1 \mathrm{~N} 1$ influenza in pregnant and postpartum women: population based cohort study. BMJ 340: c1279.

56. Verrall A, Norton K, Rooker S, Dee S, Olsen L, et al. (2010) Hospitalizations for pandemic (H1N1) 2009 among Maori and Pacific Islanders, New Zealand. Emerg Infect Dis 16: 100-102.

57. Dee S, Javathissa S (2010) Clinical and epidemiological characteristics of the hospitalised patients due to pandemic H1N1 2009 viral infection: experience at Hutt Hospital, New Zealand. N Z Med J 123: 45-53.

58. Sachedina N, Donaldson LJ (2010) Paediatric mortality related to pandemic influenza A H1N1 infection in England: an observational population-based study. Lancet 376: 1846-1852.

59. Kelly PM, Kotsimbos T, Reynolds A, Wood-Baker R, Hancox B, et al. (2011) FluCAN 2009: initial results from sentinel surveillance for adult influenza and pneumonia in eight Australian hospitals. Med J Aust 194: 169-174.

60. Chien YS, Su CP, Tsai HT, Huang AS, Lien CE, et al. (2010) Predictors and outcomes of respiratory failure among hospitalized pneumonia patients with 2009 H1N1 influenza in Taiwan. J Infect 60: 168-174.

61. Subramony H, Lai FY, Ang LW, Cutter JL, Lim PL, et al. (2010) An epidemiological study of 1348 cases of pandemic H1N1 influenza admitted to Singapore Hospitals from July to September 2009. Ann Acad Med Singapore 39: 283-288.

62. Satterwhite L, Mehta A, Martin GS (2010) Novel findings from the second wave of adult pH1N1 in the United States. Crit Care Med 38: 2059-2061.

63. Bandaranayake D, Jacobs M, Baker M, Hunt D, Wood T, et al. (2011) The second wave of 2009 pandemic influenza $\mathrm{A}(\mathrm{H} 1 \mathrm{~N} 1)$ in New Zealand, JanuaryOctober 2010. Euro Surveillance: Bulletin Europeen sur les Maladies Transmissibles $=$ European Communicable Disease Bulletin 16.
64. Reyes L, Arvelo W, Estevez A, Gray J, Moir JC, et al. (2010) Population-based surveillance for 2009 pandemic influenza A (H1N1) virus in Guatemala, 2009. Influenza Other Respi Viruses 4: 129-140.

65. Louriz M, Mahraoui C, Azzouzi A, El Fassy Fihri MT, Zeggwagh AA, et al. (2010) Clinical features of the initial cases of 2009 pandemic influenza A (H1N1) virus infection in an university hospital of Morocco. Int Arch Med 3: 26. 17557682-3-26.

66. Lahlou Amine I, Bajjou T, El Rhaffouli H, Laraqui A, Hilali F, et al. (2011) Pandemic influenza A(H1N1)2009 in Morocco: experience of the Mohammed V Military Teaching Hospital, Rabat, 12 June to 24 December 2009. Euro Surveill 16.

67. Jagannatha Rao SR, Rao MJ, Swamy N, Umapathy BL (2011) Profile of H1N1 infection in a tertiary care center. Indian J Pathol Microbiol 54: 323-325.

68. Chacko J, Gagan B, Ashok E, Radha M, Hemanth HV (2010) Critically ill patients with $2009 \mathrm{H} 1 \mathrm{~N} 1$ infection in an Indian ICU. Indian J Crit Care Med 14: 77-82.

69. Parakh A, Kumar A, Kumar V, Dutta AK, Khare S (2010) Pediatric hospitalizations associated with 2009 pandemic influenza A (H1N1): an experience from a tertiary care center in north India. Indian J Pediatr 77: 981-985.

70. Ramakrishna K, Peter JV, Karthik G, Abraham AM, Surekha V, et al. (2011) Influenza A (H1N1) 2009 pandemic: was there a difference in the two waves in patients requiring admission to the intensive-care unit? Clin Microbiol Infect 17: 1355-1358.

71. Pramanick A, Rathore S, Peter JV, Moorthy M, Lionel J (2011) Pandemic (H1N1) 2009 virus infection during pregnancy in South India. Int J Gynaecol Obstet 113: 32-35.

72. Puvanalingam A, Rajendiran C, Sivasubramanian K, Ragunanthanan S, Suresh S, et al. (2011) Case series study of the clinical profile of H1N1 swine flu influenza. J Assoc Physicians India 59: 14-16.

73. Sharma V, Verma PK, Gupta S, Sharma A (2010) Mortality from Influenza A/ $\mathrm{H} 1 \mathrm{~N} 1$ in a tertiary care teaching institution in North India. J Infect Dev Ctries 4: 468-471.

74. Chudasama RK, Patel UV, Verma PB, Amin CD, Savaria D, et al. (2011) Clinico-epidemiological features of the hospitalized patients with 2009 pandemic influenza A (H1N1) virus infection in Saurashtra region, India (September, 2009 to February, 2010). Lung India 28: 11-16.

75. Chudasama RK, Patel UV, Verma PB, Fichadiya N, Svariya DR, et al. (2010) Pediatric hospitalizations for 2009 influenza A (H1N1) in Saurashtra region, India. J Pediatr Sci 4: e27.

76. Chudasama RK, Patel UV, Verma PB (2010) Hospitalizations associated with 2009 influenza A (H1N1) and seasonal influenza in Saurashtra region, India. J Infect Dev Ctries 4: 834-841.

77. Chudasama RK, Patel UV, Verma PB, Amin CD, Shah MH, et al. (2010) Characteristics of Fatal Cases of Pandemic Influenza A (H1N1) from September 2009 to January 2010 in Saurashtra Region, India. Online J Health Allied Scs 9:

78. Chudasama RK, Verma PB, Amin CD, Gohel B, Savariya D, et al. (2010) Correlates of severe disease in patients admitted with 2009 pandemic influenza A (H1N1) infection in Saurashtra region, India. Indian J Crit Care Med 14: 113-120.

79. Gupta BD, Purohit A (2011) A clinical study of hospitalized H1N1 infected children in Western Rajasthan. J Trop Pediatr 57: 87-90.

80. Naseem A, Satti S, Khan MA, Saeed W (2011) A clinical account of hospitalized 2009 pandemic influenza A (H1N1) cases. J Coll Physicians Surg Pak 21: 97102.

81. Van Kerkhove MD, Vandemaele KA, Shinde V, Jaramillo-Gutierrez G, Koukounari A, et al. (2011) Risk factors for severe outcomes following 2009 influenza A (H1N1) infection: a global pooled analysis. PLoS Med 8: e1001053.

82. Schanzer DL, Langley JM, Tam TW (2007) Influenza-attributed hospitalization rates among pregnant women in Canada 1994-2000. J Obstet Gynaecol Can 29: 622-629.

83. Hancock K, Veguilla V, Lu X, Zhong W, Butler EN, et al. (2009) Cross-reactive antibody responses to the 2009 pandemic H1N1 influenza virus. N Engl J Med 361: 1945-1952.

84. Bhopal R (2004) Glossary of terms relating to ethnicity and race: for reflection and debate. J Epidemiol Community Health 58: 441-445. 